Supporting Information for "Sequential and environmental dependence of conformation in a small opioid peptide"

Alexandra C. Schwartz, ${ }^{1}$ Dashiell W. Jay,${ }^{1}$ Stuart Parnham,${ }^{2 \dagger}$ and Michael W. Giuliano ${ }^{1 *}$

${ }^{1}$ Department of Chemistry and Biochemistry, College of Charleston, Charleston, SC 29424

2 Department of Biochemistry and Molecular Biology, Medical University of South Carolina, Charleston, SC 29425

*corresponding author: giulianomw@cofc.edu

Table of Contents

Page(s)

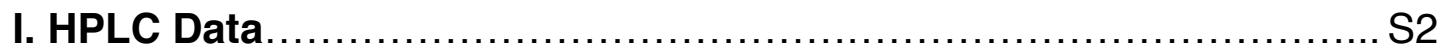

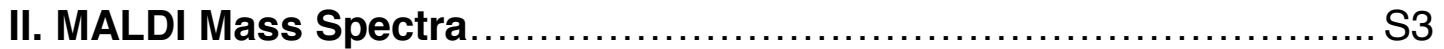

III. Molecular Dynamics Scripts and Initial Coordinates................. S4-13

IV. NMR Data and Structure Statistics for Peptides $1 \ldots \ldots \ldots \ldots \ldots \ldots . . . \ldots 14-39$

IVa. Aggregation Control ${ }^{1} \mathrm{H}$ NMR Spectra......................... $14-15$

IVb. Tabulated ${ }^{1} \mathrm{H}$ Chemical Shifts ............................... S16-17

IVc. ROEs/NOEs Used for Structure Calculations and cis/trans isomer assignment............................................S18-21

IVd. Ensembles and Statistics for Structures of Peptide 1........ S22-27

IVe. NMR Spectra for Peptide 1 ................................... S28-37

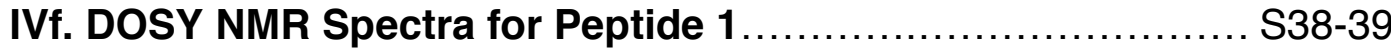

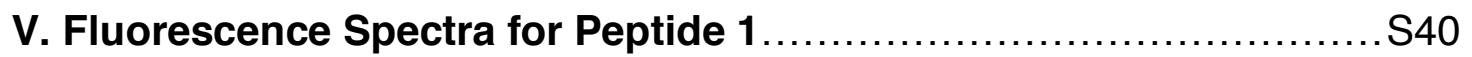

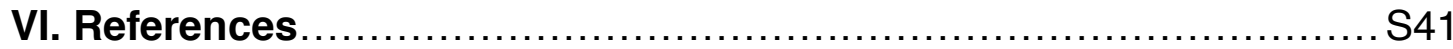

Note: Structural figures contained within the manuscript and this document were prepared with Pymol software. ${ }^{1}$ Statistics and structural ensembles in section IVd were obtained using CNS software ${ }^{2,3}$ which (cf. manuscript Experimental Section) was used to carry out the simulated annealing calculations. NMR and mass spectrometry data were processed and plotted in Mestrenova v. 12.0.2-20910. 


\section{HPLC Data}

Method: $1 \mathrm{~mL} / \mathrm{min}$. flowrate on $150 \mathrm{~mm}$ long Restek C18 "aqueous" column with $4.6 \mathrm{~mm}$ I.D. and $5 \mathrm{~mm}$ particle size. Peptides were purified to $>95 \%$ by HPLC, traces for 1 are shown below the time program. Solvent A: $0.05 \%(v / v)$ 2,2,2-trifluoroacetic acid in $\mathrm{H} 2 \mathrm{O}$. Solvent B: $0.05 \%(\mathrm{v} / \mathrm{v})$ 2,2,2-trifluoroacetic acid in acetonitrile. Note that the baseline deformation and large peak

Time $\% \mathrm{~B}$

0-50 min.

$10-60$

50-51 min.

60-95

51-56min.

95

56-57 min.

95-10

57-72 min.

10

Peptide 1-endomorphin-1

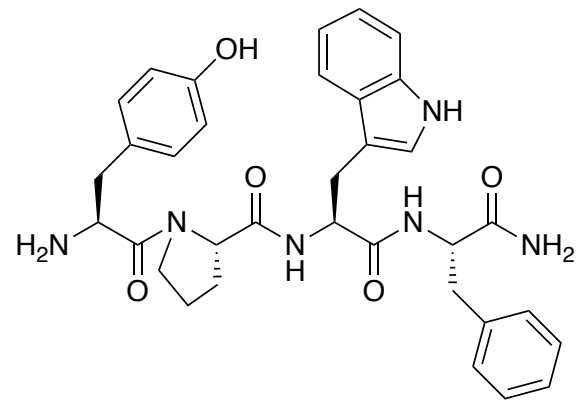

mAU

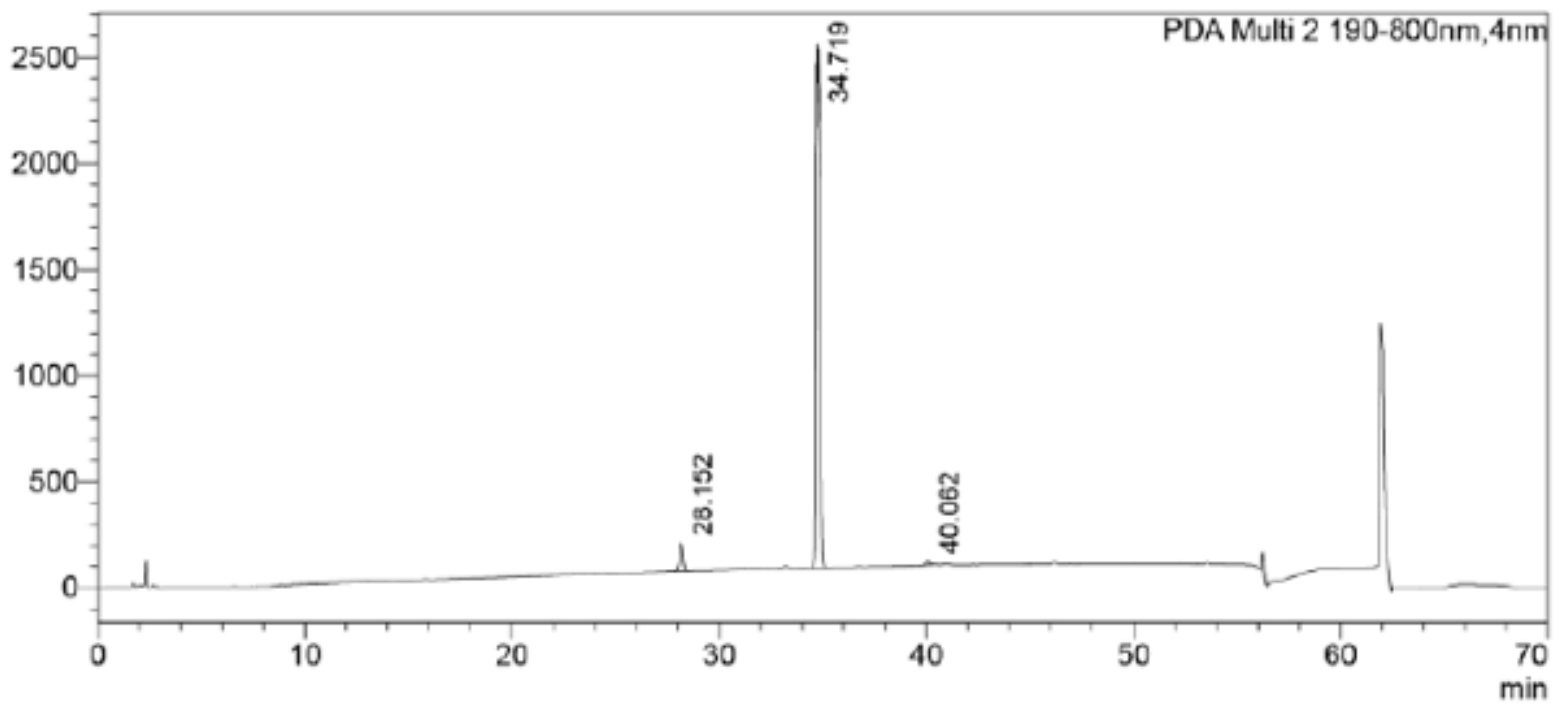

\begin{tabular}{|r|r|r|r|r|}
\multicolumn{3}{|l}{ PDA Ch2 190-800nm } \\
Peak\# Ret. Time & Height & \multicolumn{1}{|c|}{ Area } & Area\% \\
\hline 1 & 28.152 & 130975 & 1499202 & 4.276 \\
\hline 2 & 34.719 & 2383746 & 33358731 & 95.144 \\
\hline 3 & 40.062 & 18262 & 203239 & 0.580 \\
\hline Total & & 2532982 & 35061172 & 100.000 \\
\hline
\end{tabular}


II. MALDI Mass Spectra

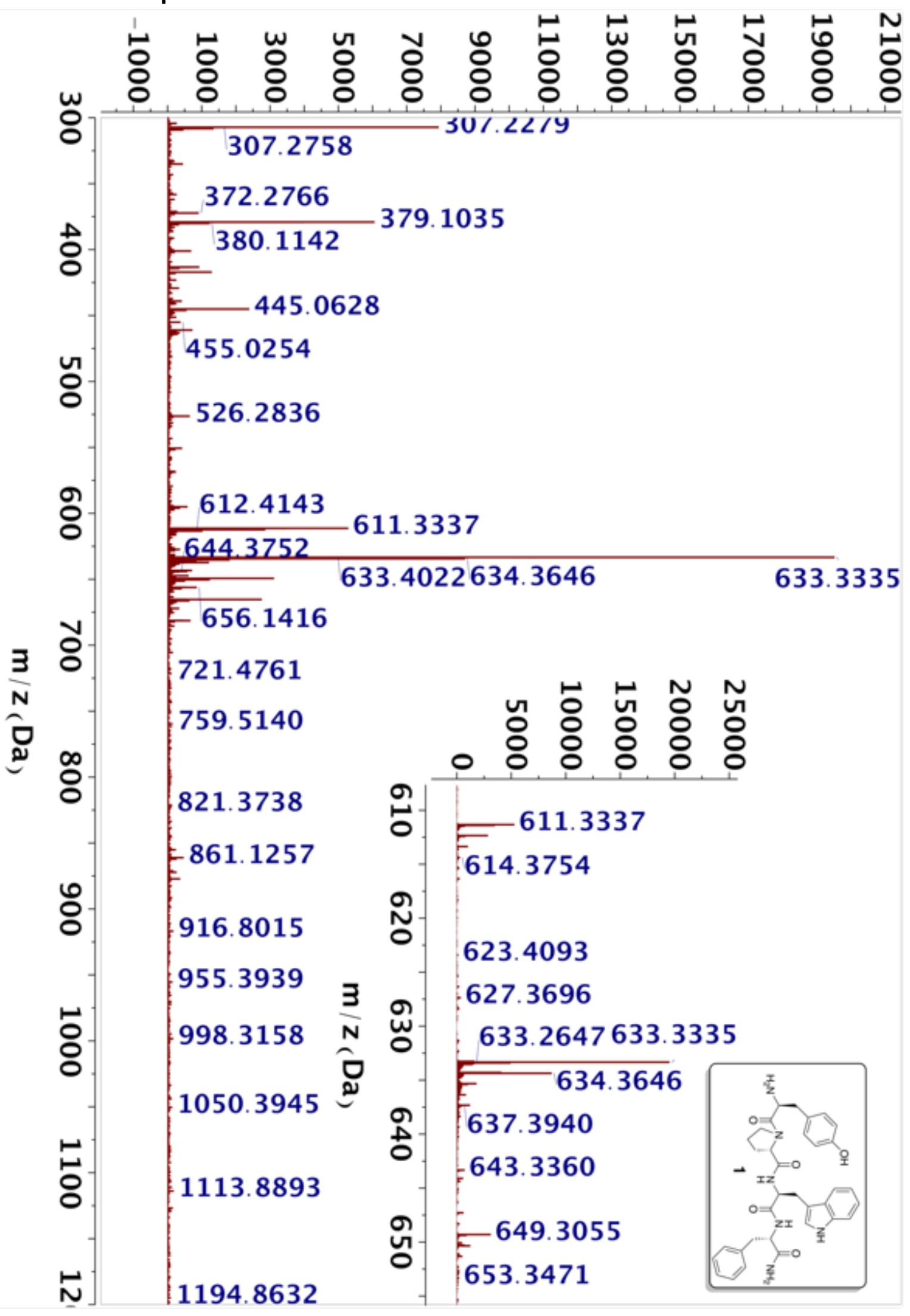




\section{Molecular Dynamics Scripts and Initial Coordinates}

Peptide 1 - endomorphin-1

Initial coordinates: (to be fed into $V M D^{4}$ and CHARMM22 forcefield for parameterization)

\begin{tabular}{|c|c|c|c|c|c|c|c|c|c|c|}
\hline ATOM & 1 & $\mathrm{~N}$ & TYR X & 22 & 1.163 & -4.503 & 5.501 & 1.00 & 0.00 & P1 \\
\hline ATOM & 2 & HT1 & TYR X & 22 & 0.643 & -4.025 & 4.793 & 0.00 & 0.00 & P1 \\
\hline ATOM & 3 & HT2 & TYR X & 22 & 0.981 & -4.091 & 6.394 & 0.00 & 0.00 & P1 \\
\hline ATOM & 4 & HT3 & TYR X & 22 & 0.912 & -5.471 & 5.514 & 0.00 & 0.00 & P1 \\
\hline ATOM & 5 & CA & TYR $X$ & 22 & 2.588 & -4.386 & 5.205 & 1.00 & 0.00 & P1 \\
\hline ATOM & 6 & $\mathrm{HA}$ & TYR X & 22 & 2.792 & -4.863 & 4.228 & 1.00 & 0.00 & P1 \\
\hline ATOM & 7 & CB & TYR X & 22 & 3.028 & -2.893 & 5.174 & 1.00 & 0.00 & P1 \\
\hline ATOM & 8 & HB1 & TYR X & 22 & 2.779 & -2.420 & 6.149 & 0.00 & 0.00 & P1 \\
\hline ATOM & 9 & HB2 & TYR X & 22 & 4.124 & -2.831 & 5.023 & 1.00 & 0.00 & P1 \\
\hline ATOM & 10 & CG & TYR X & 22 & 2.366 & -2.002 & 4.116 & 1.00 & 0.00 & P1 \\
\hline ATOM & 11 & CD1 & TYR X & 22 & 2.783 & -2.050 & 2.782 & 1.00 & 0.00 & P1 \\
\hline ATOM & 12 & HD1 & TYR X & 22 & 3.581 & -2.715 & 2.482 & 1.00 & 0.00 & P1 \\
\hline ATOM & 13 & CE1 & TYR $X$ & 22 & 2.164 & -1.247 & 1.828 & 1.00 & 0.00 & P1 \\
\hline АTOM & 14 & HE1 & TYR X & 22 & 2.480 & -1.287 & 0.796 & 1.00 & 0.00 & P1 \\
\hline ATOM & 15 & CZ & TYR X & 22 & 1.130 & -0.392 & 2.201 & 1.00 & 0.00 & P1 \\
\hline ATOM & 16 & $\mathrm{OH}$ & TYR X & 22 & 0.524 & 0.392 & 1.261 & 1.00 & 0.00 & P1 \\
\hline ATOM & 17 & $\mathrm{HH}$ & TYR X & 22 & -0.160 & 0.909 & 1.692 & 1.00 & 0.00 & P1 \\
\hline ATOM & 18 & CD2 & TYR X & 22 & 1.329 & -1.140 & 4.484 & 1.00 & 0.00 & P1 \\
\hline ATOM & 19 & HD2 & TYR X & 22 & 0.992 & -1.101 & 5.511 & 1.00 & 0.00 & P1 \\
\hline ATOM & 20 & CE2 & TYR $X$ & 22 & 0.712 & -0.338 & 3.529 & 1.00 & 0.00 & P1 \\
\hline ATOM & 21 & HE2 & TYR X & 22 & -0.092 & 0.319 & 3.825 & 1.00 & 0.00 & P1 \\
\hline ATOM & 22 & C & TYR X & 22 & 3.417 & -5.094 & 6.249 & 1.00 & 0.00 & P1 \\
\hline ATOM & 23 & 0 & TYR X & 22 & 3.190 & -4.974 & 7.456 & 1.00 & 0.00 & P1 \\
\hline ATOM & 24 & $\mathrm{~N}$ & PRO X & 23 & 4.528 & -5.952 & 5.814 & 1.00 & 0.00 & P1 \\
\hline АТОМ & 25 & $C D$ & PRO & 23 & 5.402 & -5.165 & 4.972 & 1.00 & 0.00 & P1 \\
\hline ATOM & 26 & HD1 & PRO X & 23 & 5.009 & -4.298 & 4.665 & 0.00 & 0.00 & P1 \\
\hline ATOM & 27 & HD2 & PRO X & 23 & 5.647 & -5.732 & 4.070 & 1.00 & 0.00 & P1 \\
\hline ATOM & 28 & CA & PRO $X$ & 23 & 5.160 & -6.511 & 7.001 & 1.00 & 0.00 & P1 \\
\hline АTOM & 29 & $\mathrm{HA}$ & PRO X & 23 & 4.956 & -7.582 & 7.075 & 1.00 & 0.00 & P1 \\
\hline ATOM & 30 & CB & PRO $X$ & 23 & 6.647 & -6.253 & 6.719 & 1.00 & 0.00 & P1 \\
\hline ATOM & 31 & HB1 & PRO X & 23 & 7.199 & -6.162 & 7.548 & 0.00 & 0.00 & P1 \\
\hline ATOM & 32 & HB2 & PRO $X$ & 23 & 7.046 & -7.083 & 6.132 & 1.00 & 0.00 & P1 \\
\hline ATOM & 33 & CG & PRO & 23 & 6.638 & -4.982 & 5.856 & 1.00 & 0.00 & P1 \\
\hline АТОМ & 34 & HG1 & PRO & 23 & 6.603 & -4.147 & 6.405 & 0.00 & 0.00 & P1 \\
\hline ATOM & 35 & HG2 & PRO $X$ & 23 & 7.552 & -4.866 & 5.269 & 1.00 & 0.00 & P1 \\
\hline ATOM & 36 & C & PRO $X$ & 23 & 4.663 & -5.823 & 8.284 & 1.00 & 0.00 & P1 \\
\hline ATOM & 37 & 0 & PRO X & 23 & 4.568 & -4.597 & 8.338 & 1.00 & 0.00 & P1 \\
\hline ATOM & 38 & $\mathrm{~N}$ & TRP $x$ & 24 & 4.299 & -6.635 & 9.454 & 1.00 & 0.00 & P1 \\
\hline ATOM & 39 & $\mathrm{HN}$ & TRP $x$ & 24 & 4.265 & -7.596 & 9.717 & 0.00 & 0.00 & P1 \\
\hline ATOM & 40 & CA & TRP $x$ & 24 & 3.875 & -5.697 & 10.488 & 1.00 & 0.00 & P1 \\
\hline ATOM & 41 & $\mathrm{HA}$ & TRP $x$ & 24 & 4.285 & -4.695 & 10.259 & 1.00 & 0.00 & P1 \\
\hline ATOM & 42 & CB & TRP & 24 & 2.322 & -5.648 & 10.524 & 1.00 & 0.00 & P1 \\
\hline ATOM & 43 & HB1 & TRP $x$ & 24 & 1.950 & -6.692 & 10.627 & 0.00 & 0.00 & P1 \\
\hline ATOM & 44 & HB2 & TRP $x$ & 24 & 1.978 & -5.050 & 11.389 & 1.00 & 0.00 & P1 \\
\hline ATOM & 45 & CG & TRP $X$ & 24 & 1.670 & -5.060 & 9.268 & 1.00 & 0.00 & P1 \\
\hline ATOM & 46 & CD1 & TRP $x$ & 24 & 1.155 & -5.802 & 8.186 & 1.00 & 0.00 & P1 \\
\hline ATOM & 47 & HD1 & TRP $x$ & 24 & 1.157 & -6.884 & 8.140 & 1.00 & 0.00 & P1 \\
\hline ATOM & 48 & NE1 & TRP $x$ & 24 & 0.698 & -4.963 & 7.151 & 1.00 & 0.00 & P1 \\
\hline ATOM & 49 & HE1 & TRP $x$ & 24 & 0.315 & -5.230 & 6.238 & 1.00 & 0.00 & P1 \\
\hline ATOM & 50 & CE2 & TRP & 24 & 0.952 & -3.684 & 7.625 & 1.00 & 0.00 & P1 \\
\hline ATOM & 51 & CD2 & TRP $x$ & 24 & 1.544 & -3.734 & 8.912 & 1.00 & 0.00 & P1 \\
\hline ATOM & 52 & CE3 & TRP $X$ & 24 & 1.916 & -2.540 & 9.581 & 1.00 & 0.00 & P1 \\
\hline ATOM & 53 & HE3 & TRP $x$ & 24 & 2.380 & -2.570 & 10.557 & 1.00 & 0.00 & P1 \\
\hline ATOM & 54 & CZ3 & TRP $X$ & 24 & 1.668 & -1.321 & 8.949 & 1.00 & 0.00 & P1 \\
\hline ATOM & 55 & HZ3 & TRP $x$ & 24 & 1.939 & -0.402 & 9.449 & 1.00 & 0.00 & P1 \\
\hline ATOM & 56 & CZ2 & TRP $x$ & 24 & 0.718 & -2.439 & 7.003 & 1.00 & 0.00 & P1 \\
\hline ATOM & 57 & $\mathrm{HZ2}$ & TRP $x$ & 24 & 0.268 & -2.395 & 6.022 & 1.00 & 0.00 & P1 \\
\hline ATOM & 58 & $\mathrm{CH} 2$ & TRP $x$ & 24 & 1.076 & -1.270 & 7.680 & 1.00 & 0.00 & P1 \\
\hline АТОМ & 59 & $\mathrm{HH} 2$ & TRP $x$ & 24 & 0.892 & -0.312 & 7.218 & 1.00 & 0.00 & P1 \\
\hline ATOM & 60 & C & TRP $x$ & 24 & 4.404 & -6.108 & 11.842 & 1.00 & 0.00 & P1 \\
\hline
\end{tabular}




\begin{tabular}{|c|c|c|c|c|c|c|c|c|c|c|}
\hline ATOM & 61 & 0 & TRP $\mathrm{X}$ & 24 & 4.353 & -7.272 & 12.235 & 1.00 & 0.00 & P1 \\
\hline ATOM & 62 & $\mathrm{~N}$ & PHE $X$ & 25 & 4.997 & -5.085 & 12.716 & 1.00 & 0.00 & P1 \\
\hline АTOM & 63 & $\mathrm{HN}$ & PHE $X$ & 25 & 5.187 & -4.105 & 12.713 & 0.00 & 0.00 & P1 \\
\hline ATOM & 64 & CA & PHE $X$ & 25 & 5.410 & -5.777 & 13.934 & 1.00 & 0.00 & P1 \\
\hline ATOM & 65 & $\mathrm{HA}$ & PHE $X$ & 25 & 4.856 & -6.732 & 14.010 & 1.00 & 0.00 & P1 \\
\hline ATOM & 66 & CB & PHE $X$ & 25 & 6.944 & -6.054 & 13.897 & 1.00 & 0.00 & P1 \\
\hline ATOM & 67 & HB1 & PHE $X$ & 25 & 7.487 & -5.086 & 13.824 & 0.00 & 0.00 & P1 \\
\hline АТОМ & 68 & HB2 & PHE $X$ & 25 & 7.249 & -6.557 & 14.836 & 1.00 & 0.00 & P1 \\
\hline ATOM & 69 & CG & PHE $X$ & 25 & 7.462 & -6.884 & 12.712 & 1.00 & 0.00 & P1 \\
\hline ATOM & 70 & CD1 & PHE $X$ & 25 & 7.831 & -6.239 & 11.526 & 1.00 & 0.00 & P1 \\
\hline ATOM & 71 & HD1 & PHE $X$ & 25 & 7.769 & -5.162 & 11.450 & 1.00 & 0.00 & P1 \\
\hline АTOM & 72 & CE1 & PHE $X$ & 25 & 8.225 & -6.982 & 10.418 & 1.00 & 0.00 & P1 \\
\hline ATOM & 73 & HE1 & PHE $X$ & 25 & 8.478 & -6.476 & 9.497 & 1.00 & 0.00 & P1 \\
\hline ATOM & 74 & $C Z$ & PHE $X$ & 25 & 8.269 & -8.372 & 10.493 & 1.00 & 0.00 & P1 \\
\hline ATOM & 75 & $\mathrm{HZ}$ & PHE $X$ & 25 & 8.569 & -8.946 & 9.630 & 1.00 & 0.00 & P1 \\
\hline ATOM & 76 & CD2 & PHE $X$ & 25 & 7.509 & -8.278 & 12.782 & 1.00 & 0.00 & P1 \\
\hline ATOM & 77 & HD2 & PHE X & 25 & 7.215 & -8.789 & 13.689 & 1.00 & 0.00 & P1 \\
\hline ATOM & 78 & CE2 & PHE $X$ & 25 & 7.914 & -9.020 & 11.675 & 1.00 & 0.00 & P1 \\
\hline ATOM & 79 & HE2 & PHE $X$ & 25 & 7.942 & -10.099 & 11.731 & 1.00 & 0.00 & P1 \\
\hline ATOM & 80 & C & PHE $X$ & 25 & 5.092 & -4.953 & 15.159 & 1.00 & 0.00 & P1 \\
\hline АTOM & 81 & 0 & PHE $X$ & 25 & 4.541 & -3.820 & 15.078 & 1.00 & 0.00 & P1 \\
\hline ATOM & 82 & NT & PHE $X$ & 25 & 5.386 & -5.454 & 15.973 & 0.00 & 0.00 & P1 \\
\hline ATOM & 83 & HT1 & PHE $X$ & 25 & 5.175 & -4.908 & 16.784 & 0.00 & 0.00 & P1 \\
\hline ATOM & 84 & HT2 & PHE X & 25 & 5.787 & -6.325 & 15.692 & 0.00 & 0.00 & P1 \\
\hline
\end{tabular}

$N A M D^{5}$ script - . conf file

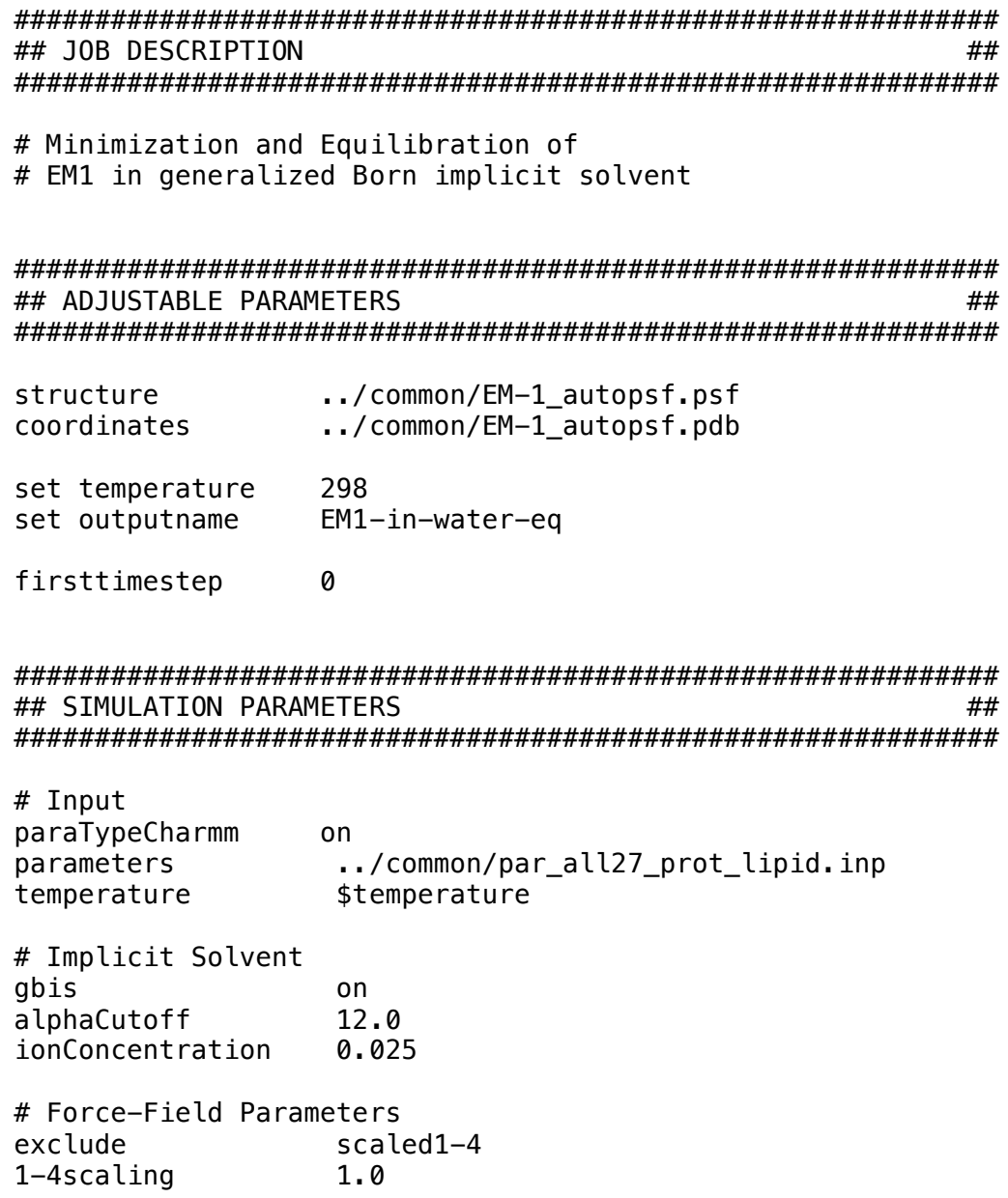




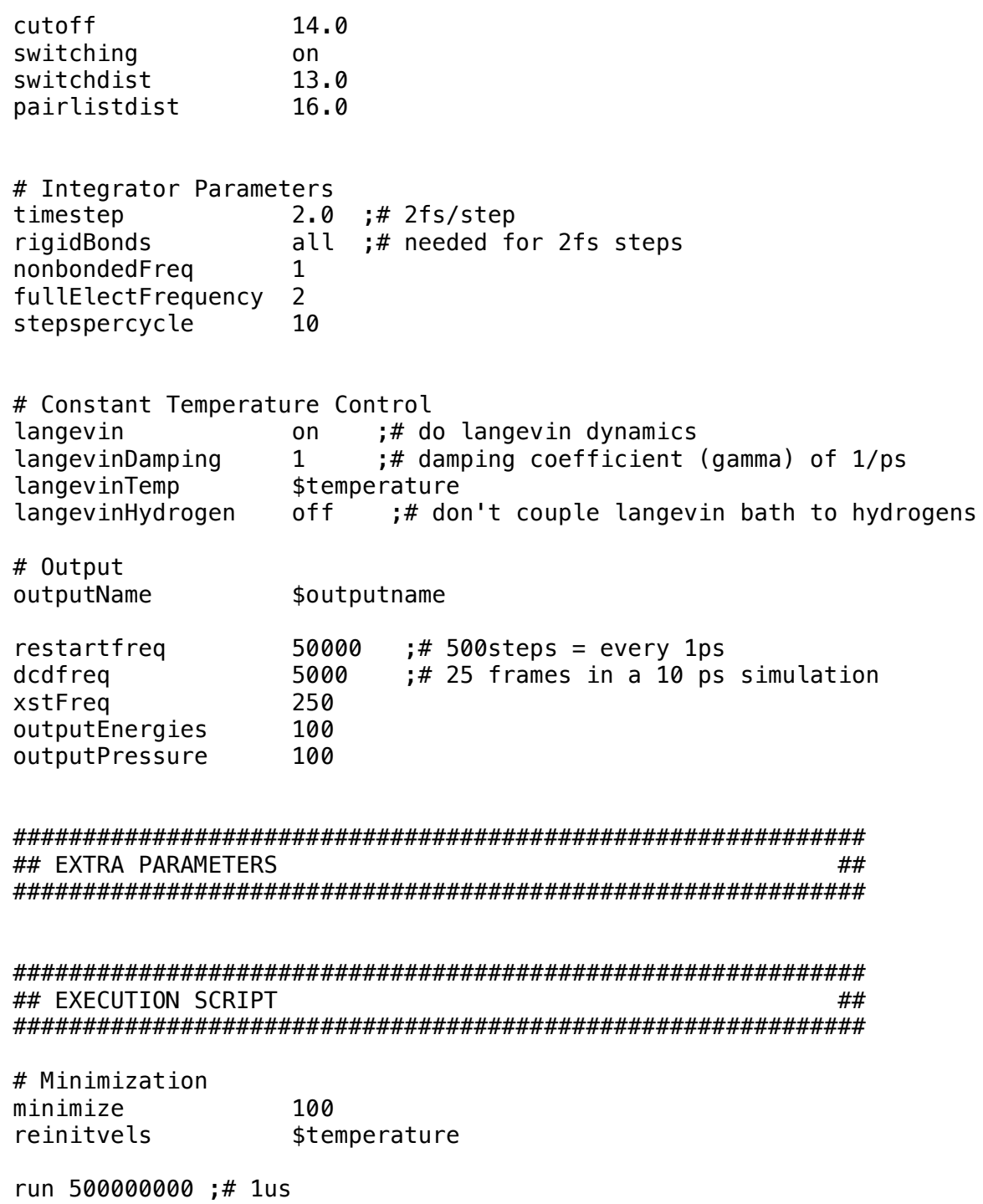


Peptide 2 - "message peptide"

Initial Coordinates: (to be fed into VMD ${ }^{4}$ and CHARMM22 forcefield for parameterization)

\begin{tabular}{|c|c|c|c|c|c|c|c|c|c|c|c|}
\hline ATOM & 1 & $\mathrm{~N}$ & TYR & $P$ & 22 & -0.813 & -2.199 & 1.423 & 1.00 & 0.00 & P1 \\
\hline ATOM & 2 & HT1 & TYR & $P$ & 22 & -1.333 & -1.721 & 0.715 & 1.00 & 0.00 & P1 \\
\hline ATOM & 3 & HT2 & TYR & $P$ & 22 & -0.995 & -1.787 & 2.316 & 1.00 & 0.00 & P1 \\
\hline ATOM & 4 & HT3 & TYR & P & 22 & -1.064 & -3.167 & 1.436 & 1.00 & 0.00 & P1 \\
\hline ATOM & 5 & CA & TYR & P & 22 & 0.612 & -2.082 & 1.127 & 1.00 & 0.00 & P1 \\
\hline ATOM & 6 & HA & TYR & $P$ & 22 & 0.816 & -2.559 & 0.150 & 1.00 & 0.00 & P1 \\
\hline АTOM & 7 & $C B$ & TYR & $P$ & 22 & 1.052 & -0.589 & 1.096 & 1.00 & 0.00 & P1 \\
\hline АTOM & 8 & HB1 & TYR & P & 22 & 0.803 & -0.116 & 2.071 & 1.00 & 0.00 & P1 \\
\hline ATOM & 9 & HB2 & TYR & $P$ & 22 & 2.148 & -0.527 & 0.945 & 1.00 & 0.00 & P1 \\
\hline ATOM & 10 & CG & TYR & $\mathrm{P}$ & 22 & 0.390 & 0.302 & 0.038 & 1.00 & 0.00 & P1 \\
\hline АTOM & 11 & CD1 & TYR & P & 22 & 0.807 & 0.254 & -1.296 & 1.00 & 0.00 & P1 \\
\hline АTOM & 12 & HD1 & TYR & $P$ & 22 & 1.605 & -0.411 & -1.596 & 1.00 & 0.00 & P1 \\
\hline АТОM & 13 & CE1 & TYR & P & 22 & 0.188 & 1.057 & -2.250 & 1.00 & 0.00 & P1 \\
\hline ATOM & 14 & HE1 & TYR & $\mathrm{P}$ & 22 & 0.504 & 1.017 & -3.282 & 1.00 & 0.00 & P1 \\
\hline ATOM & 15 & $\mathrm{CZ}$ & TYR & $P$ & 22 & -0.846 & 1.912 & -1.877 & 1.00 & 0.00 & P1 \\
\hline ATOM & 16 & $\mathrm{OH}$ & TYR & $P$ & 22 & -1.452 & 2.696 & -2.817 & 1.00 & 0.00 & P1 \\
\hline ATOM & 17 & $\mathrm{HH}$ & TYR & $P$ & 22 & -2.136 & 3.213 & -2.386 & 1.00 & 0.00 & P1 \\
\hline АTOM & 18 & CD2 & TYR & $P$ & 22 & -0.647 & 1.164 & 0.406 & 1.00 & 0.00 & P1 \\
\hline ATOM & 19 & HD2 & TYR & $\mathrm{P}$ & 22 & -0.984 & 1.203 & 1.433 & 1.00 & 0.00 & P1 \\
\hline АTOM & 20 & CE2 & TYR & $P$ & 22 & -1.264 & 1.966 & -0.549 & 1.00 & 0.00 & P1 \\
\hline ATOM & 21 & HE2 & TYR & P & 22 & -2.068 & 2.623 & -0.253 & 1.00 & 0.00 & P1 \\
\hline АTOM & 22 & C & TYR & $P$ & 22 & 1.441 & -2.790 & 2.171 & 1.00 & 0.00 & P1 \\
\hline ATOM & 23 & 0 & TYR & $P$ & 22 & 1.214 & -2.670 & 3.378 & 1.00 & 0.00 & P1 \\
\hline ATOM & 24 & $\mathrm{~N}$ & GLY & $P$ & 23 & 2.552 & -3.649 & 1.736 & 1.00 & 0.00 & P1 \\
\hline ATOM & 25 & $\mathrm{HN}$ & GLY & P & 23 & 2.975 & -3.942 & 0.879 & 1.00 & 0.00 & P1 \\
\hline АTOM & 26 & CA & GLY & $P$ & 23 & 3.154 & -4.186 & 2.953 & 1.00 & 0.00 & P1 \\
\hline ATOM & 27 & HA1 & GLY & P & 23 & 2.821 & -5.209 & 3.061 & 1.00 & 0.00 & P1 \\
\hline ATOM & 28 & HA2 & GLY & $\mathrm{P}$ & 23 & 2.877 & -3.540 & 3.775 & 1.00 & 0.00 & P1 \\
\hline ATOM & 29 & C & GLY & P & 23 & 4.660 & -4.193 & 2.853 & 1.00 & 0.00 & P1 \\
\hline ATOM & 30 & 0 & GLY & $P$ & 23 & 5.247 & -4.587 & 1.842 & 1.00 & 0.00 & P1 \\
\hline ATOM & 31 & $\mathrm{~N}$ & GLY & $P$ & 24 & 5.453 & -3.716 & 3.996 & 1.00 & 0.00 & P1 \\
\hline ATOM & 32 & $\mathrm{HN}$ & GLY & $P$ & 24 & 5.292 & -3.351 & 4.912 & 1.00 & 0.00 & P1 \\
\hline АTOM & 33 & CA & GLY & $P$ & 24 & 6.854 & -3.843 & 3.604 & 1.00 & 0.00 & P1 \\
\hline ATOM & 34 & HA1 & GLY & P & 24 & 7.214 & -2.856 & 3.347 & 1.00 & 0.00 & P1 \\
\hline ATOM & 35 & HA2 & GLY & $P$ & 24 & 6.911 & -4.561 & 2.797 & 1.00 & 0.00 & P1 \\
\hline ATOM & 36 & C & GLY & $\mathrm{P}$ & 24 & 7.690 & -4.362 & 4.749 & 1.00 & 0.00 & P1 \\
\hline АTOM & 37 & 0 & GLY & $P$ & 24 & 7.575 & -3.921 & 5.895 & 1.00 & 0.00 & P1 \\
\hline АTOM & 38 & $\mathrm{~N}$ & PHE & $P$ & 25 & 8.672 & -5.425 & 4.489 & 1.00 & 0.00 & P1 \\
\hline АTOM & 39 & $\mathrm{HN}$ & PHE & $P$ & 25 & 9.006 & -5.977 & 3.727 & 1.00 & 0.00 & P1 \\
\hline ATOM & 40 & CA & PHE & $\mathrm{P}$ & 25 & 9.315 & -5.710 & 5.769 & 1.00 & 0.00 & P1 \\
\hline ATOM & 41 & HA & PHE & $P$ & 25 & 9.167 & -4.846 & 6.445 & 1.00 & 0.00 & P1 \\
\hline АTOM & 42 & CB & PHE & P & 25 & 8.698 & -6.994 & 6.403 & 1.00 & 0.00 & P1 \\
\hline ATOM & 43 & HB1 & PHE & $\mathrm{P}$ & 25 & 8.857 & -7.852 & 5.714 & 1.00 & 0.00 & P1 \\
\hline ATOM & 44 & HB2 & PHE & $P$ & 25 & 9.210 & -7.213 & 7.361 & 1.00 & 0.00 & P1 \\
\hline АTOM & 45 & CG & PHE & $P$ & 25 & 7.183 & -6.972 & 6.657 & 1.00 & 0.00 & P1 \\
\hline АTOM & 46 & CD1 & PHE & P & 25 & 6.306 & -7.385 & 5.647 & 1.00 & 0.00 & P1 \\
\hline АTOM & 47 & HD1 & PHE & $P$ & 25 & 6.695 & -7.735 & 4.700 & 1.00 & 0.00 & P1 \\
\hline ATOM & 48 & CE1 & PHE & $P$ & 25 & 4.931 & -7.295 & 5.832 & 1.00 & 0.00 & P1 \\
\hline ATOM & 49 & HE1 & PHE & $\mathrm{P}$ & 25 & 4.264 & -7.588 & 5.035 & 1.00 & 0.00 & P1 \\
\hline ATOM & 50 & $\mathrm{CZ}$ & PHE & $P$ & 25 & 4.422 & -6.808 & 7.033 & 1.00 & 0.00 & P1 \\
\hline ATOM & 51 & $\mathrm{HZ}$ & PHE & $P$ & 25 & 3.354 & -6.734 & 7.172 & 1.00 & 0.00 & P1 \\
\hline ATOM & 52 & CD2 & PHE & $P$ & 25 & 6.666 & -6.485 & 7.860 & 1.00 & 0.00 & P1 \\
\hline ATOM & 53 & HD2 & PHE & $\mathrm{P}$ & 25 & 7.332 & -6.151 & 8.644 & 1.00 & 0.00 & P1 \\
\hline АTOM & 54 & CE2 & PHE & P & 25 & 5.288 & -6.406 & 8.049 & 1.00 & 0.00 & P1 \\
\hline АTOM & 55 & HE2 & PHE & P & 25 & 4.893 & -6.022 & 8.978 & 1.00 & 0.00 & P1 \\
\hline АTOM & 56 & C & PHE & $P$ & 25 & 10.800 & -5.917 & 5.595 & 1.00 & 0.00 & P1 \\
\hline ATOM & 57 & 0 & PHE & $P$ & 25 & 11.209 & -6.109 & 6.487 & 0.00 & 0.00 & P1 \\
\hline ATOM & 58 & NT & PHE & $\mathrm{P}$ & 25 & 11.032 & -5.814 & 4.628 & 0.00 & 0.00 & P1 \\
\hline ATOM & 59 & HT1 & PHE & P & 25 & 12.016 & -5.951 & 4.512 & 0.00 & 0.00 & P1 \\
\hline АTOM & 60 & HT2 & PHE & $P$ & 25 & 10.199 & -5.610 & 4.113 & 0.00 & 0.00 & P1 \\
\hline
\end{tabular}




\section{$N A M D^{5}$ script - .conf file}

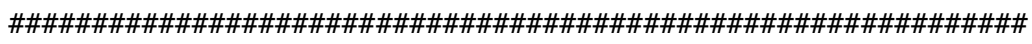
\#\# JOB DESCRIPTION

\# Minimization and Equilibration of

\# message peptide in generalized Born implicit solvent

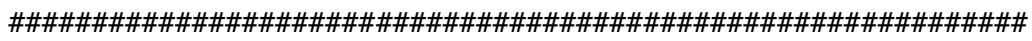
\#\# ADJUSTABLE PARAMETERS

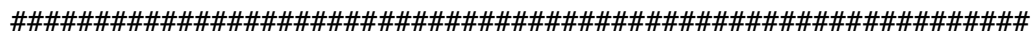

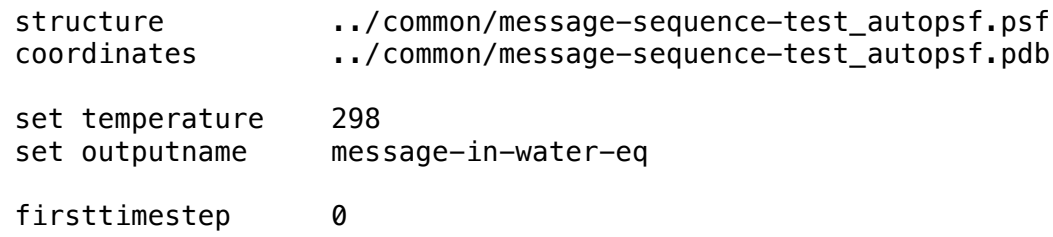




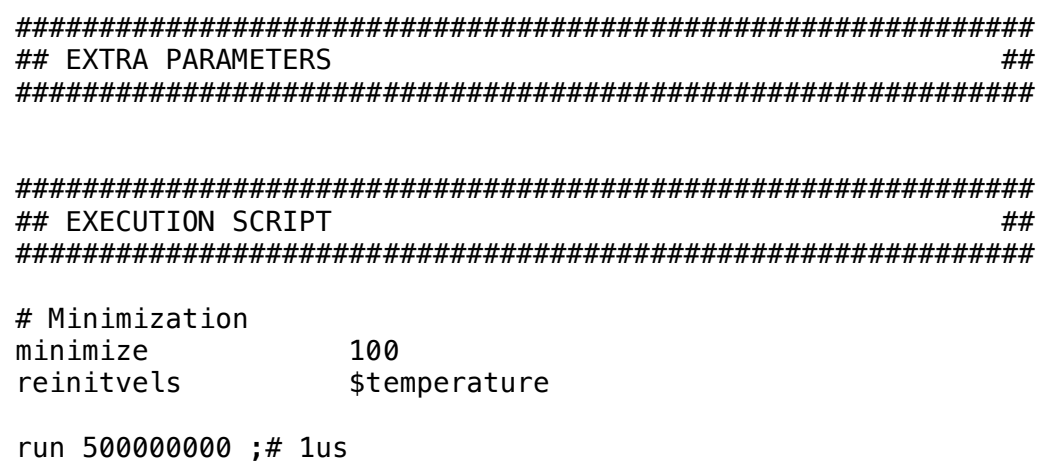




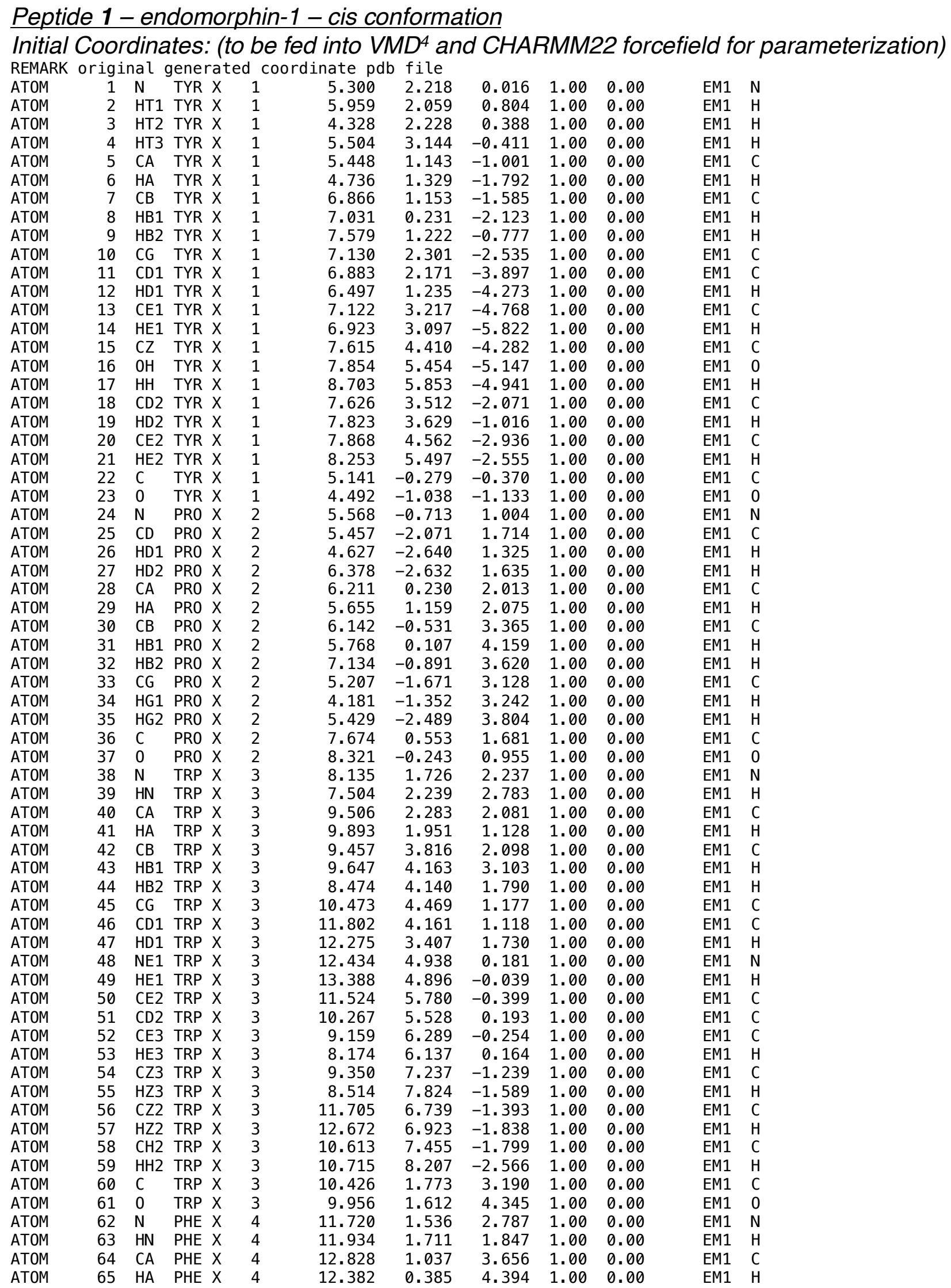




\begin{tabular}{|c|c|c|c|c|c|c|c|c|c|c|}
\hline ATOM & 66 & CB & PHE $X$ & 4 & 13.828 & 0.213 & 2.817 & 1.00 & 0.00 & EM1 \\
\hline ATOM & 67 & HB1 & PHE $X$ & 4 & 14.620 & 0.864 & 2.477 & 1.00 & 0.00 & EM1 \\
\hline ATOM & 68 & HB2 & PHE $X$ & 4 & 13.314 & -0.195 & 1.959 & 1.00 & 0.00 & EM1 \\
\hline ATOM & 69 & CG & PHE $X$ & 4 & 14.457 & -0.934 & 3.563 & 1.00 & 0.00 & EM1 \\
\hline ATOM & 70 & CD1 & PHE $X$ & 4 & 13.867 & -2.188 & 3.561 & 1.00 & 0.00 & EM1 \\
\hline ATOM & 71 & HD1 & PHE $X$ & 4 & 12.945 & -2.339 & 3.018 & 1.00 & 0.00 & EM1 \\
\hline ATOM & 72 & CE1 & PHE $X$ & 4 & 14.443 & -3.242 & 4.244 & 1.00 & 0.00 & EM1 \\
\hline ATOM & 73 & HE1 & PHE $X$ & 4 & 13.973 & -4.214 & 4.235 & 1.00 & 0.00 & EM1 \\
\hline ATOM & 74 & CZ & PHE $X$ & 4 & 15.621 & -3.051 & 4.939 & 1.00 & 0.00 & EM1 \\
\hline ATOM & 75 & $\mathrm{HZ}$ & PHE $X$ & 4 & 16.074 & -3.873 & 5.473 & 1.00 & 0.00 & EM1 \\
\hline ATOM & 76 & CD2 & PHE $X$ & 4 & 15.640 & -0.756 & 4.264 & 1.00 & 0.00 & EM1 \\
\hline ATOM & 77 & HD2 & PHE $X$ & 4 & 16.109 & 0.217 & 4.273 & 1.00 & 0.00 & EM1 \\
\hline ATOM & 78 & CE2 & PHE $X$ & 4 & 16.220 & -1.806 & 4.949 & 1.00 & 0.00 & EM1 \\
\hline ATOM & 79 & HE2 & PHE $X$ & 4 & 17.142 & -1.654 & 5.492 & 1.00 & 0.00 & EM1 \\
\hline ATOM & 80 & C & PHE X & 4 & 13.539 & 2.192 & 4.405 & 1.00 & 0.00 & EM1 \\
\hline ATOM & 81 & 0 & PHE $X$ & 4 & 13.801 & 2.089 & 5.603 & 1.00 & 0.00 & EM1 \\
\hline ATOM & 82 & NT & PHE $X$ & 4 & 13.852 & 3.294 & 3.706 & 1.00 & 0.00 & EM1 \\
\hline ATOM & 83 & HT1 & PHE $X$ & 4 & 14.302 & 3.948 & 4. 314 & 0.00 & 0.00 & EM1 \\
\hline ATOM & 84 & HT2 & PHE $X$ & 4 & 13.554 & 3.175 & 2.759 & 0.00 & 0.00 & EM1 \\
\hline
\end{tabular}


$N A M D^{5}$ script - . conf file

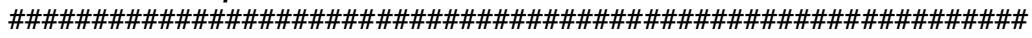
\#\# JOB DESCRIPTION

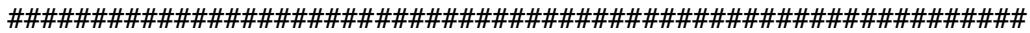

\# Minimization and Equilibration of

\# EM1 with cis Tyr-Pro bond in generalized Born implicit solvent

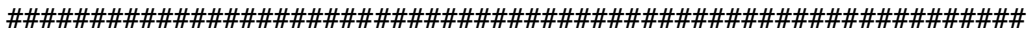
\#\# ADJUSTABLE PARAMETERS

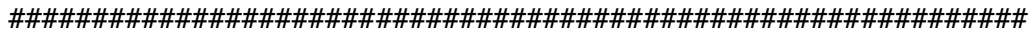

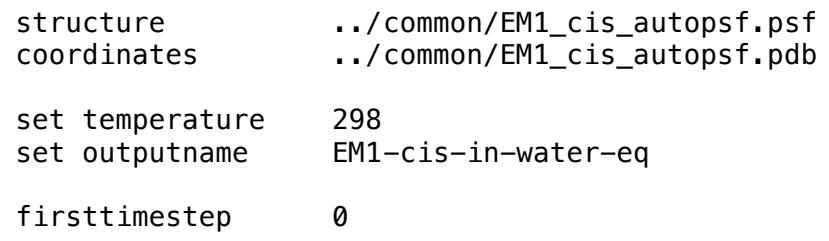




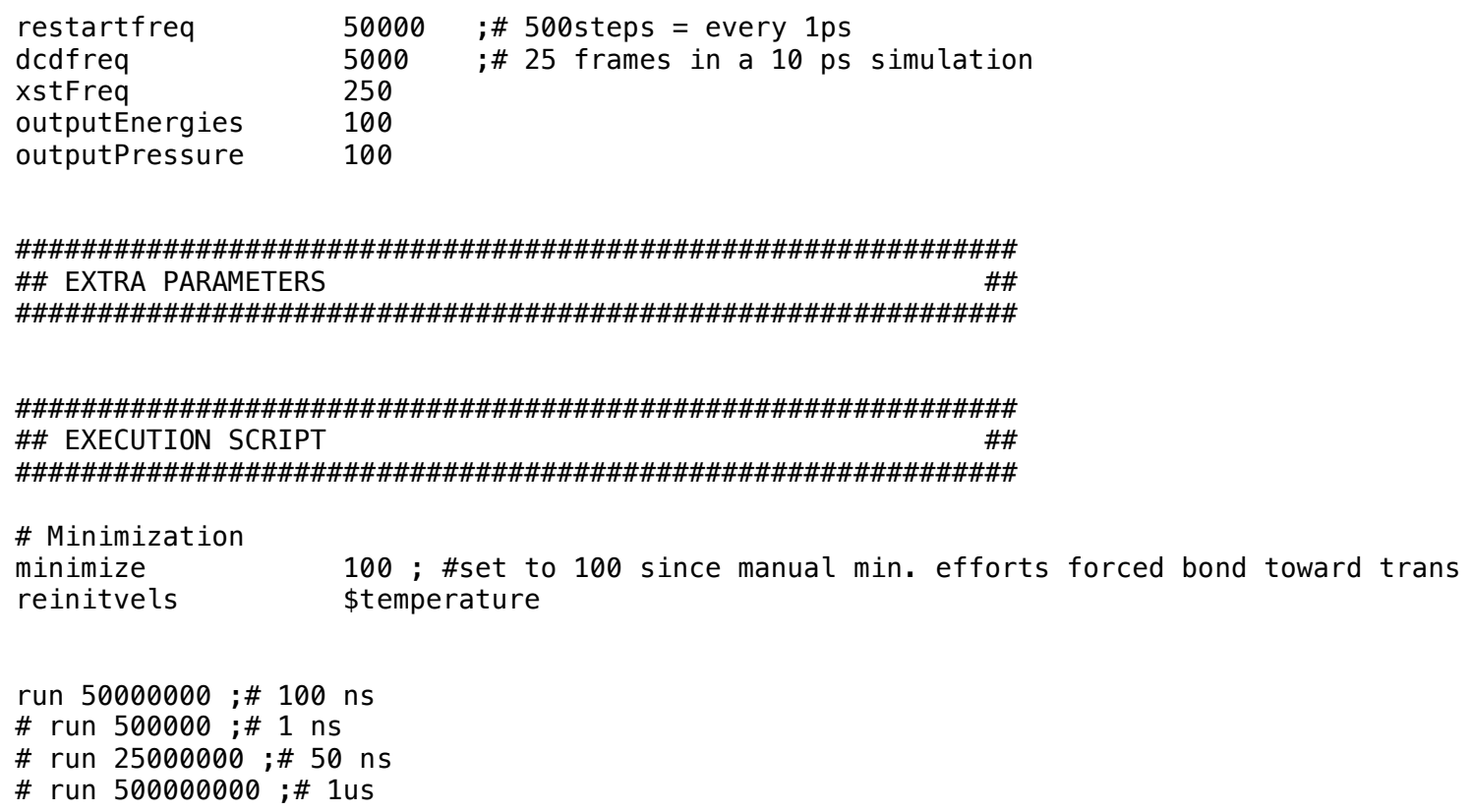

\section{ExtraBonds file}

dihedral $22212327200 \quad-172.66351318359375$

dihedral $\begin{array}{llllll}36 & 35 & 39 & 200 & 0.05692644417285919\end{array}$

dihedral $60596163200-0.05981924384832382$ 


\section{NMR Data and Structure Statistics for Peptide 1}

\section{IVa. Aggregation Control ${ }^{1} \mathrm{H}$ NMR Spectra}

The stacked spectra below (amide and aromatic regions shown) were used (as discussed in the manuscript's experimental section) to determine an optimal peptide concentration of $2.0 \mathrm{mM}$ for peptide 1. Higher concentrations showed signs of peak broadening and dispersion in their amide and aromatic regions, indicating intermediate exchange likely due to non-specific aggregation in solution. ${ }^{6,7}$ Sample conditions are indicated with the spectra below.

Peptide 1 - endomorphin-1

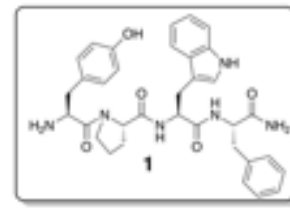

common sample conditions: $10 \mathrm{mM}$

phosphate buffer, $\mathrm{pH} 7.0$

$10 \%(v / v) \mathrm{D}_{2} \mathrm{O}$ in $\mathrm{H}_{2} \mathrm{O}$,

referenced externally to

deuterated DSS at 0.00

ppm.

\section{$5.0 \mathrm{mM}$}
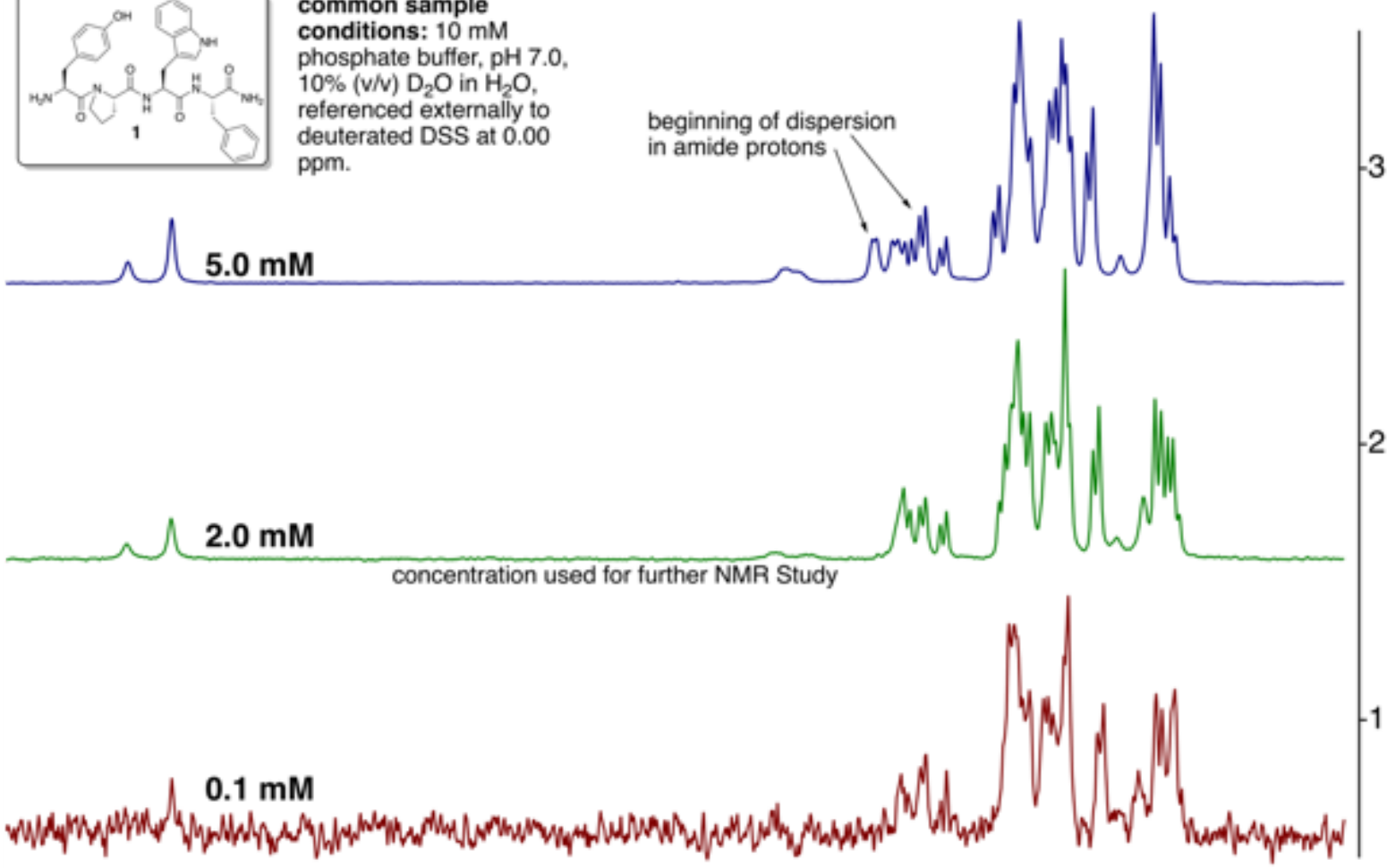

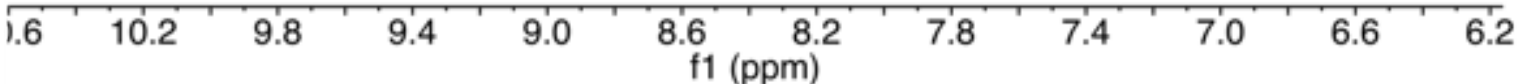

Figure S1. Amide and and aromatic region of ${ }^{1} \mathrm{H}$ NMR spectra over a 50 -fold range of peptide concentration in buffered aqueous solution for Peptide 1. Spectra collected at $298 \mathrm{~K}$. 


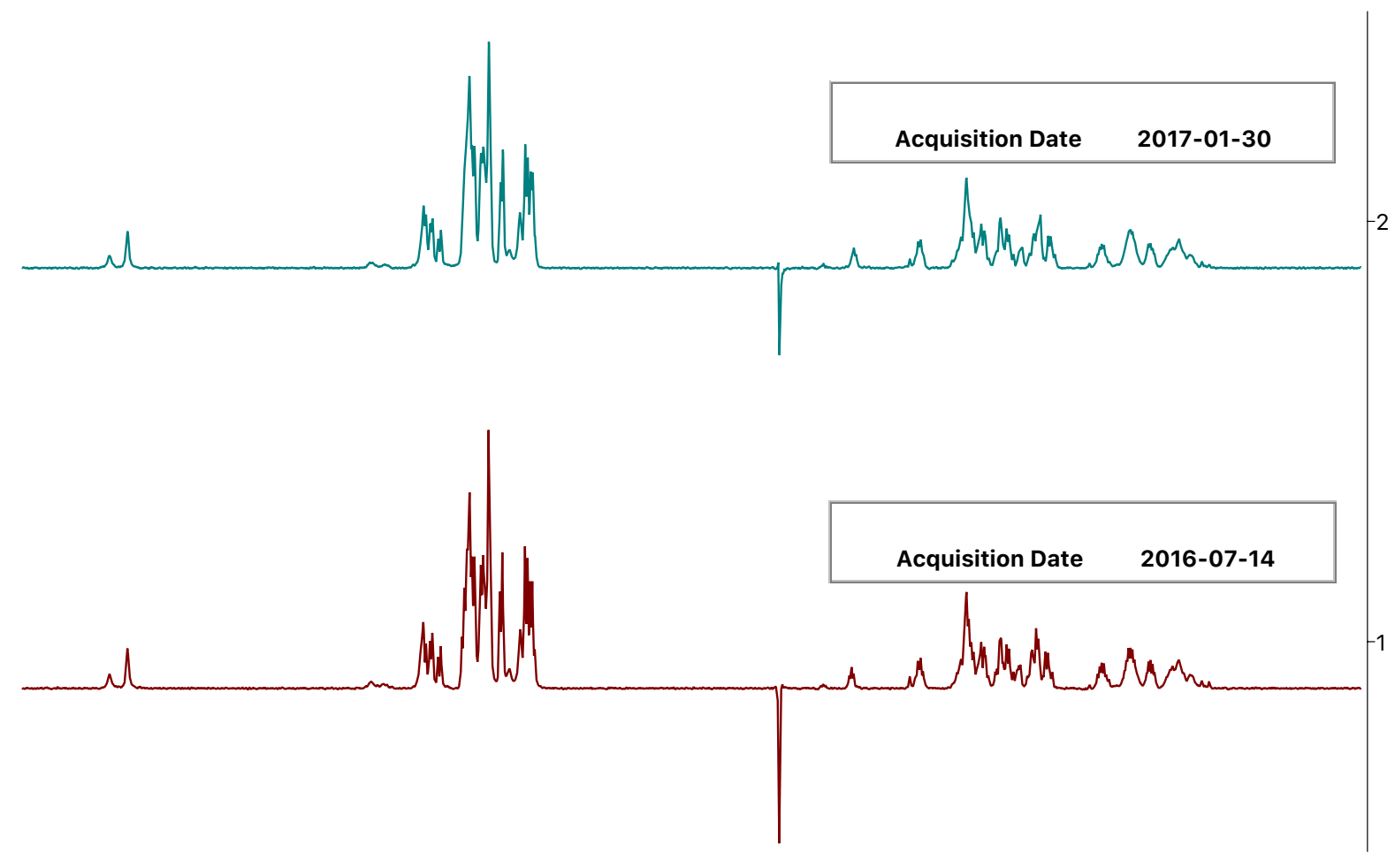

\begin{tabular}{llllllllllllllllllllllllllll}
\hline .0 & 10.5 & 10.0 & 9.5 & 9.0 & 8.5 & 8.0 & 7.5 & 7.0 & 6.5 & 6.0 & 5.5 & 5.0 & 4.5 & 4.0 & 3.5 & 3.0 & 2.5 & 2.0 & 1.5 & 1.0 & 0.5 & 0.0
\end{tabular}

Figure S2. Stacked spectrum of $1 \mathrm{H}$ 1D Spectra of peptide 1 taken from the identical sample stored varyingly at room temperature, in the refrigerator, or in a freezer over the course of six months. Appended dates are stamped directly from the raw data files. Lack of significant change in the spectra supports that $2.0 \mathrm{mM}$ is an appropriate concentration for experimental work carried out on peptide 1 in solution free of aggregation. Spectra were collected in $10 \mathrm{mM}$ phosphate buffer in $10 \%(\mathrm{v} / \mathrm{v}) \mathrm{D}_{2} \mathrm{O}$ in $\mathrm{H}_{2} \mathrm{O}$ at a concentration of $2 \mathrm{mM}$ peptide 1 at $298 \mathrm{~K}$. 


\section{IVb. Tabulated ${ }^{1} \mathrm{H}$ Chemical Shifts}

Spectra were assigned using sequential procedures ${ }^{6-8}$ as outlined in the Experimental Section of the manuscript. The tables below represent the average chemical shift for each assigned proton, calculated from all instances of a given resonance. Header figures explaining proton nomenclature are included with each. In the instance of diastereotopic aliphatic protons, the more upfield of the two was designated "1" and the more downfield of the pair was designated "2."

Table S1. Average ${ }^{1} \mathrm{H}$ Chemical Shifts for Peptide 1 in $10 \mathrm{mM} \mathrm{pH} 7.0$ phosphate buffer assigned from overlay of 2D ${ }^{1} \mathrm{H}-{ }^{1} \mathrm{H}$ COSY, TOCSY, and ROESY spectra collected at 298K.
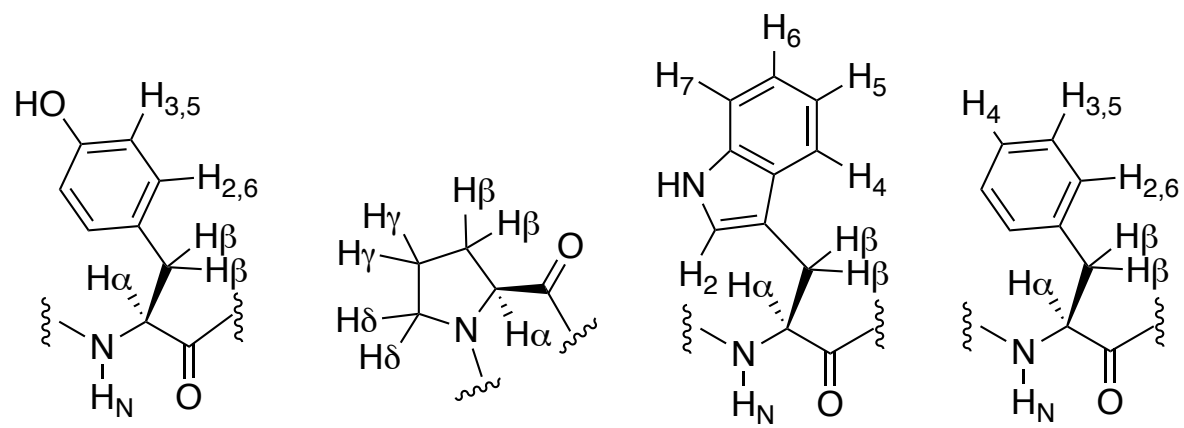

\begin{tabular}{|c|c|c|c|c|c|c|c|c|c|c|c|c|}
\hline Residue & $\begin{array}{c}\text { Proton } \\
\mathrm{H}_{\mathrm{N}} \\
\end{array}$ & $\begin{array}{c}(\delta, \\
\text { ppm) } \\
\text { H } \alpha\end{array}$ & $H \beta$ & $\mathrm{H} \gamma$ & $(\mathrm{H} 2,6)^{\star}$ & $H(3,5)^{*}$ & $\mathrm{H} 2$ & $\mathrm{H} \zeta^{* *}$ & H5 & $\mathrm{H} 6$ & $\mathrm{H} 7$ & NH1 \\
\hline Tyr(1) & --- & 4.19 & $2.57,2.70$ & -- & 7.06 & 6.82 & --- & --- & --- & --- & --- & --- \\
\hline Pro(2) & --- & 4.41 & $1.71,2.13$ & $1.86,1.91$ & $3.18,3.62$ & --- & -- & --- & --- & --- & -- & --- \\
\hline $\operatorname{Trp}(3)$ & 7.72 & 4.54 & 3.23 & --- & --- & --- & 7.14 & 7.63 & 7.20 & 7.16 & 7.37 & 10.13 \\
\hline Phe(4) & 7.73 & 4.50 & $2.85,2.95$ & --- & $\begin{array}{l}7.22- \\
7.32\end{array}$ & $\begin{array}{l}7.22- \\
7.32\end{array}$ & --- & $\begin{array}{l}7.22- \\
7.32\end{array}$ & --- & --- & --- & --- \\
\hline
\end{tabular}

* for Tyr and Phe residues, ${ }^{* *}$ for Phe residues

Note: C-terminal amide unassigned 
Table S2. Average ${ }^{1} \mathrm{H}$ Chemical Shifts for major conformer of Peptide 1 in 15 wt\% phospholipid bicelles, assigned from overlay of $2 \mathrm{D}{ }^{1} \mathrm{H}-{ }^{-1} \mathrm{H}$ COSY, TOCSY, and NOESY spectra.
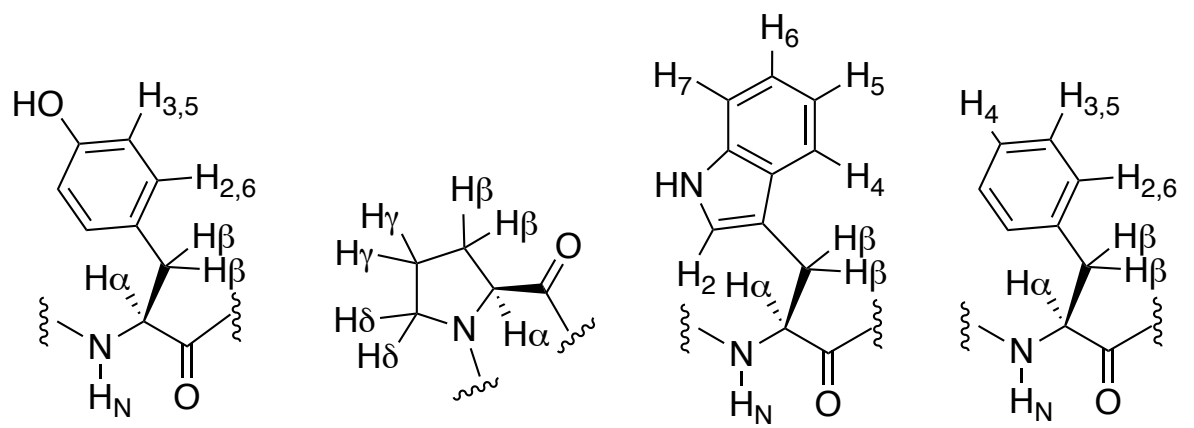

\begin{tabular}{|c|c|c|c|c|c|c|c|c|c|c|c|c|}
\hline Residue & $\begin{array}{c}\text { Proton } \\
\mathrm{H}_{\mathrm{N}}\end{array}$ & $\begin{array}{c}(\delta, \\
\text { ppm) } \\
H_{\alpha}\end{array}$ & $H \beta$ & $\mathrm{H}_{\gamma}$ & $(\mathrm{H} 2,6)^{*}$ & $H(3,5)^{*}$ & $\mathrm{H} 2$ & $H \zeta^{* *}$ & H5 & $\mathrm{H} 6$ & $\mathrm{H} 7$ & NH1 \\
\hline Tyr(1) & --- & 4.24 & $2.70,3.06$ & --- & 7.00 & 6.78 & --- & --- & --- & --- & --- & --- \\
\hline Pro(2) & --- & 4.49 & $1.93,2.13$ & 1.76 & $3.09,3.63$ & --- & --- & --- & --- & --- & --- & --- \\
\hline $\operatorname{Trp}(3)$ & 7.81 & 4.45 & 3.09 & --- & --- & --- & 7.28 & 7.56 & 7.00 & 7.06 & 7.40 & 10.47 \\
\hline Phe(4) & 7.56 & 4.61 & $2.93,3.10$ & --- & 7.21 & 7.27 & --- & 7.15 & --- & --- & --- & --- \\
\hline
\end{tabular}

Table S3. Average ${ }^{1} \mathrm{H}$ Chemical Shifts for minor conformer of Peptide 1 in 15 wt\% phospholipid bicelles, assigned from overlay of $2 \mathrm{D}{ }^{1} \mathrm{H}^{-1} \mathrm{H}$ COSY, TOCSY, and NOESY spectra.

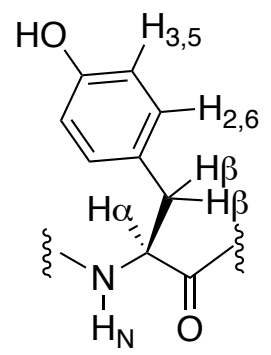

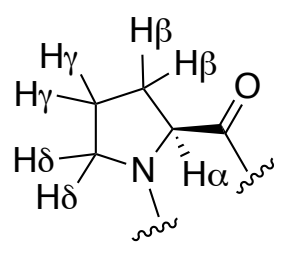

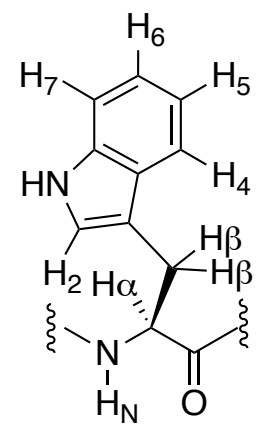<smiles>Cc1ccc(C(C)CP)c(P)c1P</smiles>

\begin{tabular}{|c|c|c|c|c|c|c|c|c|c|c|c|c|}
\hline Residue & $\begin{array}{c}\text { Proton } \\
\mathbf{H}_{N}\end{array}$ & $\begin{array}{c}(\delta, p p m) \\
H \alpha\end{array}$ & $H \beta$ & $\mathrm{H} \gamma$ & $\begin{array}{c}(\mathrm{H} 2,6)^{\star} \\
\mathrm{H} \delta\end{array}$ & $\begin{array}{c}\mathrm{H}(3,5)^{*} \\
\mathbf{H}_{\boldsymbol{\varepsilon}}\end{array}$ & $\mathrm{H} 2$ & H4 & H5 & H6 & H7 & NH1 \\
\hline Tyr(1) & --- & un. & $2.70,2.95$ & --- & 6.68 & 6.57 & --- & --- & --- & --- & --- & --- \\
\hline Pro(2) & --- & un. & un. & un. & un. & --- & --- & --- & --- & --- & --- & --- \\
\hline $\operatorname{Trp}(3)$ & un. & 4.66 & 3.03 & --- & --- & --- & 7.33 & 7.62 & 7.16 & 7.14 & 7.57 & 10.60 \\
\hline Phe(4) & un. & un. & un. & un. & un. & un. & --- & --- & --- & --- & --- & --- \\
\hline
\end{tabular}

* for Tyr and Phe residues, ${ }^{* *}$ for Phe residues, un. = unassigned due to ambiguous overlap or die-off of crosspeak intensity Note: C-terminal amide unassigned 


\section{IVc. ROEs/NOEs Used for NMR Structure Calculations}

General Notes: The bins for ROESY and NOESY-derived distances are indicated above each table and were used to generate the initial set of upper bounds. For the lipid structures of 1, generated from the restraints in Tables S6 and S7, the upper bounds of distance restraints were all set to $6.0 \AA$ for the final round of annealing. This removed any geometric violations due to potential over-restraint caused by the implicit uncertainty in distances derived from NOESY crosspeak integration.

Table S4. ROE-derived distance restraints used for calculation of the aqueous NMR structure of 1 . A lower bound of $1.8 \AA$ was used in all cases.

Bins: strong $=1.8-2.6 \AA$, medium $=1.8-3.3 \AA$, weak $=1.8-5.0 \AA$, very weak $=1.8-6.0 \AA$.
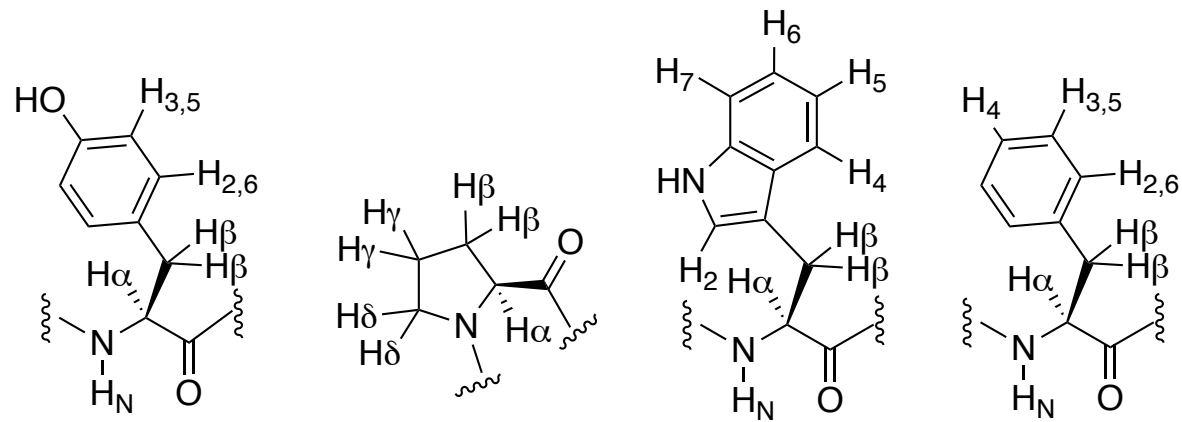

\begin{tabular}{|c|c|c|}
\hline Correlation & Observed Distance $(\AA ̊)$ & Upper Bound (§̊) \\
\hline \multicolumn{3}{|l|}{ Intraresidue } \\
\hline $\operatorname{Tyr}(1) \mathrm{H} \alpha$ to $\mathrm{H}_{2,6}$ & 3.0 & 3.3 \\
\hline $\operatorname{Tyr}(1) \mathrm{H}_{2,6}$ to $\mathrm{H} \beta$ & 2.6 & 2.6 \\
\hline $\operatorname{Tyr}(1) \mathrm{H}_{3,5}$ to $\mathrm{H} \beta$ & 4.9 & 5.0 \\
\hline $\operatorname{Trp}(3) \mathrm{H}_{4}$ to $\mathrm{H \alpha}$ & 2.4 & 2.6 \\
\hline $\operatorname{Trp}(3) \mathrm{H}_{4}$ to $\mathrm{H} \beta$ & 2.5 & 2.6 \\
\hline $\operatorname{Trp}(3) \mathrm{H}_{2}$ to $\mathrm{H} \beta$ & 2.7 & 3.3 \\
\hline \multicolumn{3}{|l|}{ Interresidue } \\
\hline $\operatorname{Tyr}(1) \mathrm{H}_{2,6}$ to $\operatorname{Pro}(2) \mathrm{H} \delta$ & 4.1 & 5.0 \\
\hline $\operatorname{Tyr}(1) \mathrm{H}_{3,5}$ to $\mathrm{Phe}(4) \mathrm{H} \beta$ & 4.2 & 5.0 \\
\hline $\operatorname{Tyr}(1) \mathrm{H}_{3,5}$ to $\operatorname{Pro}(2) \mathrm{H} \delta$ & 3.4 & 5.0 \\
\hline $\operatorname{Tyr}(1) \mathrm{H} \alpha$ to $\operatorname{Pro}(2) \mathrm{H} \delta$ & 2.1 & 2.6 \\
\hline $\operatorname{Pro}(2) \mathrm{H} \delta$ to $\operatorname{Tyr}(1) \mathrm{H} \beta$ & 3.2 & 3.3 \\
\hline Pro(2) $\mathrm{H} \gamma$ to $\operatorname{Trp}(3) \mathrm{H}_{4}$ & 3.6 & 5.0 \\
\hline $\operatorname{Trp}(3) \mathrm{HN}$ to $\operatorname{Pro}(2) \mathrm{H} \beta$ & 4.0 & 5.0 \\
\hline $\operatorname{Trp}(3) \mathrm{HN}$ to $\operatorname{Pro}(2) \mathrm{H} \alpha$ & 2.4 & 2.6 \\
\hline $\operatorname{Trp}(3) \mathrm{H}_{4}$ to $\operatorname{Pro}(2) \mathrm{H} \beta$ & 4.6 & 5.0 \\
\hline $\operatorname{Trp}(3) \mathrm{H}_{2}$ to $\mathrm{Phe}(4) \mathrm{H} \beta$ & 2.4 & 2.6 \\
\hline $\operatorname{Trp}(3) \mathrm{H} \beta$ to $\operatorname{Tyr}(1) \mathrm{H}_{3,5}$ & 4.5 & 5.0 \\
\hline Phe(4) $\mathrm{H}_{3,5}$ to $\operatorname{Trp}(3) \mathrm{H} \beta$ & 3.8 & 5.0 \\
\hline Phe(4) $\mathrm{H}_{2,6}$ to $\operatorname{Trp}(3) \mathrm{H} \beta$ & 5.0 & 5.0 \\
\hline
\end{tabular}


Table S5. NOE-derived distance restraints used for calculation of the NMR structure of the minor conformer of $\mathbf{1}$ in $15 \mathrm{wt} \%$ lipid bicelles. A lower bound of $1.8 \AA$ was used in all cases.

Bins: strong $=1.8-2.6 \AA$, medium $=1.8-3.3 \AA$, weak $=1.8-5.0 \AA$, very weak $=1.8-6.0 \AA$.
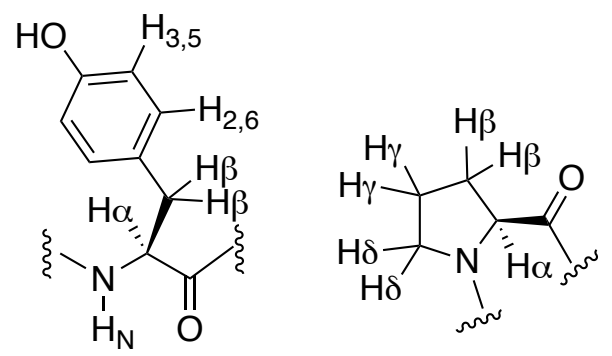

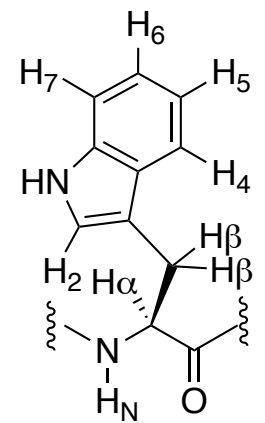<smiles>Cc1ccc(C(C)(C)C(C(=O)CP)(C(=O)CP)N(C)C)c(C)c1C</smiles>

\begin{tabular}{|c|c|c|}
\hline Correlation & Observed Distance $(\AA ̊)$ & Upper Bound ( $\AA$ ) \\
\hline \multicolumn{3}{|l|}{ Intraresidue } \\
\hline $\operatorname{Tyr}(1) \mathrm{H}_{3,5}$ to $\mathrm{H} \beta$ & 2.7 & 6.0 \\
\hline $\operatorname{Tyr}(1) \mathrm{H}_{2,6}$ to $\mathrm{H} \beta$ & 3.3 & 6.0 \\
\hline $\operatorname{Trp}(3) \mathrm{H}_{\mathrm{N}}$ to $\mathrm{H}_{4}$ & 4.3 & 6.0 \\
\hline $\operatorname{Trp}(3) \mathrm{H}_{4}$ to $\mathrm{H} \beta$ & 2.6 & 6.0 \\
\hline $\operatorname{Trp}(3) \mathrm{H}_{4}$ to $\mathrm{H} \alpha$ & 2.7 & 6.0 \\
\hline $\operatorname{Trp}(3) \mathrm{H}_{2}$ to $\mathrm{H} \beta$ & 2.7 & 6.0 \\
\hline $\operatorname{Trp}(3) \mathrm{H}_{2}$ to $\mathrm{H} \alpha$ & 2.6 & 6.0 \\
\hline \multicolumn{3}{|l|}{ Interresidue } \\
\hline $\operatorname{Tyr}(1) \mathrm{H}_{3,5}$ to $\operatorname{Trp}(3) \mathrm{H}_{5}$ & 4.2 & 6.0 \\
\hline $\operatorname{Tyr}(1) \mathrm{H}_{3,5}$ to $\operatorname{Trp}(3) \mathrm{H}_{6}$ & 4.2 & 6.0 \\
\hline $\operatorname{Tyr}(1) \mathrm{H}_{2,6}$ to $\operatorname{Trp}(3) \mathrm{H}_{5}$ & 5.6 & 6.0 \\
\hline $\operatorname{Tyr}(1) \mathrm{H}_{2,6}$ to $\operatorname{Trp}(3) \mathrm{H}_{6}$ & 5.6 & 6.0 \\
\hline $\operatorname{Tyr}(1) \mathrm{H}_{3,5}$ to $\operatorname{Trp}(3) \mathrm{H}_{7}$ & 5.5 & 6.0 \\
\hline $\operatorname{Tyr}(1) \mathrm{H}_{2,6}$ to $\operatorname{Trp}(3) \mathrm{H}_{7}$ & 5.6 & 6.0 \\
\hline $\operatorname{Tyr}(1) \mathrm{H}_{3,5}$ to $\operatorname{Trp}(3) \mathrm{H}_{4}$ & 5.3 & 6.0 \\
\hline $\operatorname{Tyr}(1) \mathrm{H}_{2,6}$ to $\operatorname{Trp}(3) \mathrm{H}_{4}$ & 6.0 & 6.0 \\
\hline $\operatorname{Trp}(3) \mathrm{H} \beta$ to $\operatorname{Tyr}(1) \mathrm{H}_{3,5}$ & 4.7 & 6.0 \\
\hline $\operatorname{Trp}(3) \mathrm{H} \beta$ to $\operatorname{Tyr}(1) \mathrm{H}_{2,6}$ & 5.7 & 6.0 \\
\hline $\operatorname{Trp}(3) \mathrm{H}_{\mathrm{N}}$ to $\operatorname{Tyr}(1) \mathrm{H}_{3,5}$ & 4.2 & 6.0 \\
\hline
\end{tabular}

Note: lack of precise integration resulted in geometric violations such that all NOE restraints were allowed to sample the entire range of boundaries from 1.8 to $6.0 \AA$. 
Table S6. NOE-derived distance restraints used for calculation of the NMR structure of the major conformer of 1 in 15 wt \% lipid bicelles. A lower bound of $1.8 \AA$ was used in all cases. See below for notes on generation of ensemble with cis peptide bond between $\operatorname{Tyr}(1)$ and Pro(2).

Bins: strong $=1.8-2.6 \AA$, medium $=1.8-3.3 \AA$, weak $=1.8-5.0 \AA$, very weak $=1.8-6.0 \AA$.
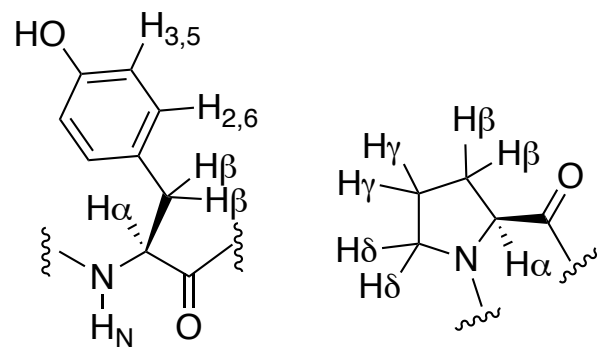

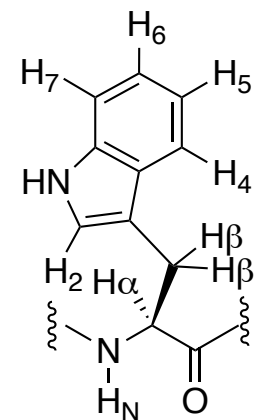<smiles>Cc1ccc(C(CP)C(CP)C(=O)O)c(C)c1C</smiles>

\begin{tabular}{|c|c|c|}
\hline Correlation & Observed Distance $(\AA)$ & Upper Bound $(\AA)$ \\
\hline \multicolumn{3}{|l|}{ Intraresidue } \\
\hline $\operatorname{Tyr}(1) \mathrm{H}_{2,6}$ to $\mathrm{H} \beta$ & 3.0 & 6.0 \\
\hline $\operatorname{Tyr}(1) \mathrm{H}_{3,5}$ to $\mathrm{H} \beta$ & 3.6 & 6.0 \\
\hline Trp(3)NH1 to $\mathrm{H}_{6}$ & 3.5 & 6.0 \\
\hline $\operatorname{Trp}(3) \mathrm{H}_{7}$ to $\mathrm{H} \beta$ & 5.4 & 6.0 \\
\hline $\operatorname{Trp}(3) \mathrm{H}_{6}$ to $\mathrm{H} \beta$ & 5.3 & 6.0 \\
\hline $\mathrm{Trp}(3) \mathrm{H}_{4}$ to $\mathrm{NH} 1$ & 3.5 & 6.0 \\
\hline Phe(4) $\mathrm{H}_{2,6}$ to $\mathrm{H} \beta$ & 2.9 & 6.0 \\
\hline Phe(4) $\mathrm{H}_{3,5}$ to $\mathrm{H} \beta$ & 3.8 & 6.0 \\
\hline Phe(4) $\mathrm{H}_{2,6}$ to $\mathrm{H} \alpha$ & 3.0 & 6.0 \\
\hline Phe(4) $\mathrm{H}_{3,5}$ to $\mathrm{H} \alpha$ & 3.6 & 6.0 \\
\hline $\mathrm{Phe}(4) \mathrm{H}_{4}$ to $\mathrm{H} \alpha$ & 3.2 & 6.0 \\
\hline \multicolumn{3}{|l|}{ Interresidue } \\
\hline $\operatorname{Tyr}(1) \mathrm{H} \beta$ to $\operatorname{Trp}(3) \mathrm{NH} 1$ & 3.7 & 6.0 \\
\hline $\operatorname{Tyr}(1) \mathrm{H} \beta$ to $\operatorname{Trp}(3) \mathrm{H}_{\mathrm{N}}$ & 6.0 & 6.0 \\
\hline $\operatorname{Tyr}(1) \mathrm{H} \beta$ to $\operatorname{Trp}(3) \mathrm{H}_{7}$ & 5.0 & 6.0 \\
\hline $\operatorname{Tyr}(1) \mathrm{H} \beta$ to $\operatorname{Trp}(3) \mathrm{H}_{6}$ & 4.9 & 6.0 \\
\hline $\operatorname{Pro}(2) \mathrm{H} \delta$ to $\operatorname{Tyr}(1) \mathrm{H}_{2,6}$ & 3.6 & 6.0 \\
\hline $\operatorname{Pro}(2) \mathrm{H} \delta$ to $\operatorname{Tyr}(1) \mathrm{H}_{3,5}$ & 4.0 & 6.0 \\
\hline${ }^{*} \operatorname{Pro}(2) \mathrm{H} \gamma$ to $\operatorname{Trp}(3) \mathrm{H}_{2}$ & 4.2 & 6.0 \\
\hline $\operatorname{Trp}(3) \mathrm{H}_{7}$ to $\operatorname{Tyr}(1) \mathrm{H}_{3,5}$ & 4.6 & 6.0 \\
\hline${ }^{*} \operatorname{Trp}(3) \mathrm{H}_{N}$ to $\operatorname{Pro}(2) \mathrm{H} \gamma$ & 4.3 & 6.0 \\
\hline $\operatorname{Trp}(3) \mathrm{H}_{N}$ to $\operatorname{Pro}(2) \mathrm{H} \beta$ & 3.9 & 6.0 \\
\hline${ }^{*} \operatorname{Trp}(3) \mathrm{H}_{5}$ to $\operatorname{Pro}(2) \mathrm{H} \gamma$ & 4.2 & 6.0 \\
\hline Phe(4) $\mathrm{H}_{4}$ to $\operatorname{Tyr}(1) \mathrm{H} \beta$ & 5.0 & 6.0 \\
\hline $\operatorname{Tyr}(1) \mathrm{H}_{2,6}$ to $\operatorname{Pro}(2) \mathrm{H} \alpha$ & $--^{* *}$ & 6.0 \\
\hline $\operatorname{Tyr}(1) \mathrm{H}_{3,5}$ to $\operatorname{Pro}(2) \mathrm{H} \alpha$ & $--^{* *}$ & 6.0 \\
\hline
\end{tabular}

${ }^{*}$ Restraints not used to allow for proline ring pseudorotation during simulated annealing, consistent with prior observation of correlation between ring pucker and cis/trans amide isomerism in proline residues. ${ }^{9}$ ${ }^{\star *}$ Observed in potentially overlapped region of spectrum so not measured and instead allowed to fluctuate across entire boundary range from 1.8 to $6.0 \AA$. 
(a)

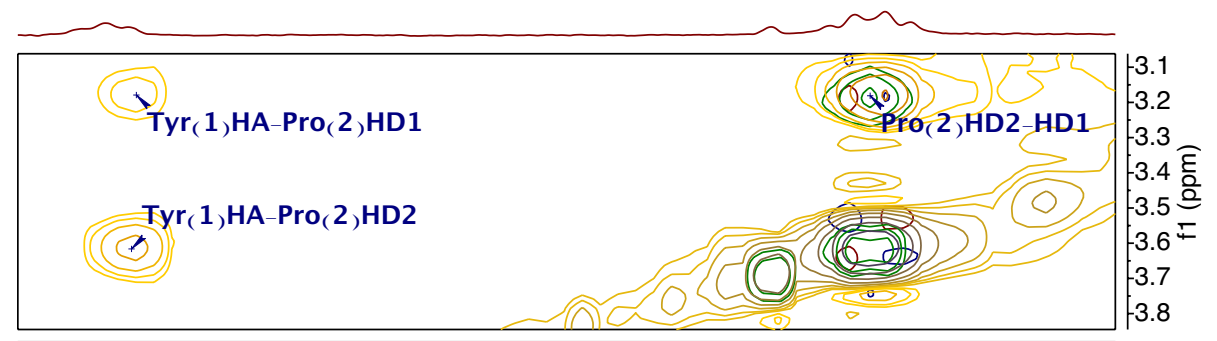

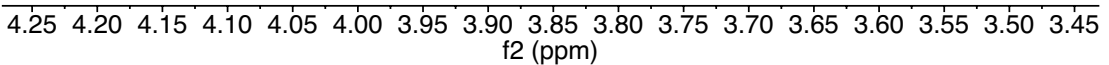

(b)

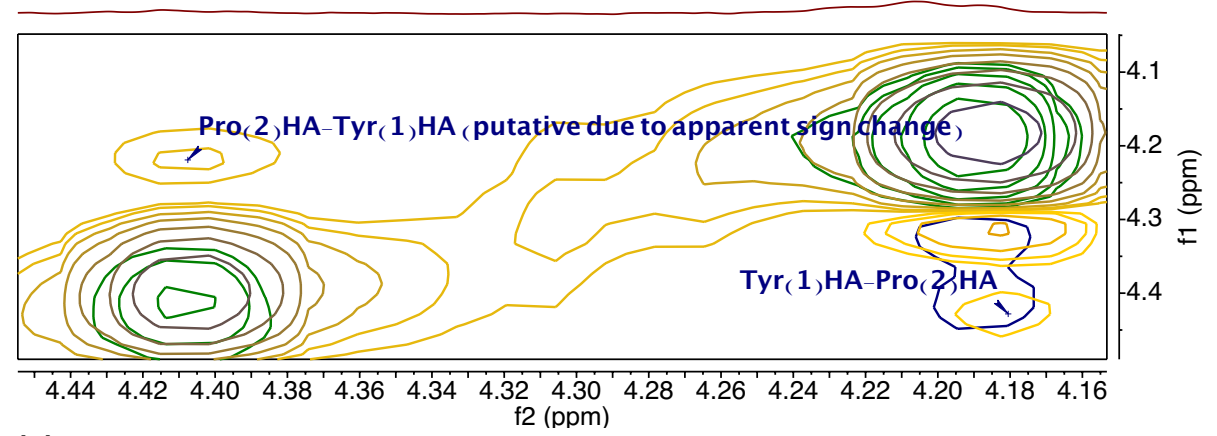

(c)

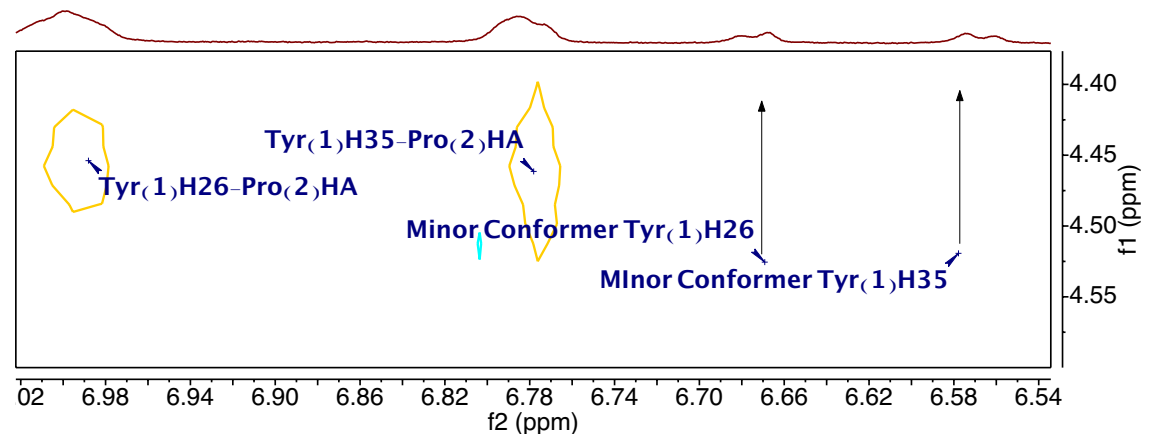

Figure S3. Cis/Trans assignment for NMR Structures of Peptide 1. (a) Tyr(1)Ho to Pro(2)H $\delta$ ROESY crosspeaks for trans assignment of major conformer in water. (b) Weak

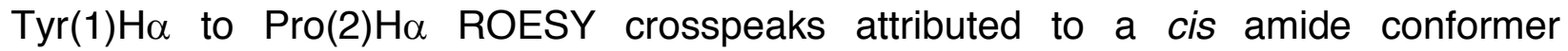
representing the minor species in solution. No other crosspeaks consistent with this observation were assignable and all other correlated well to the observed crosspeaks in (a). (c) $\operatorname{Tyr}(1) \mathrm{H}_{2,6}$ to $\operatorname{Pro}(2) \mathrm{H} \alpha$ and $\operatorname{Tyr}(1) \mathrm{H}_{3,5}$ to Pro(2) $\mathrm{H} \alpha$ NOESY crosspeaks used to assign the major conformer of 1 in 15 wt\% bicelles as having a cis amide. The absence of such crosspeaks was used to, coupled to their presence for the major conformer, infer that a trans amide linkage between $\operatorname{Tyr}(1)$ and $\operatorname{Pro}(2)$ was appropriate for the minor conformer of 1 in 15 wt\% bicelles. All samples collected at $298 \mathrm{~K}$ and, unless specified, in $10 \mathrm{mM}$ phosphate buffer at $\mathrm{pH} 7.0$ in $10 \%(\mathrm{v} / \mathrm{v}) \mathrm{D} 2 \mathrm{O}$ in $\mathrm{H} 2 \mathrm{O}$, at a peptide 1 concentration fo $2 \mathrm{mM}$. The presence of bicelles is indicated in the caption above. 
IVd. Ensembles and Statistics for Structures of Peptide 1

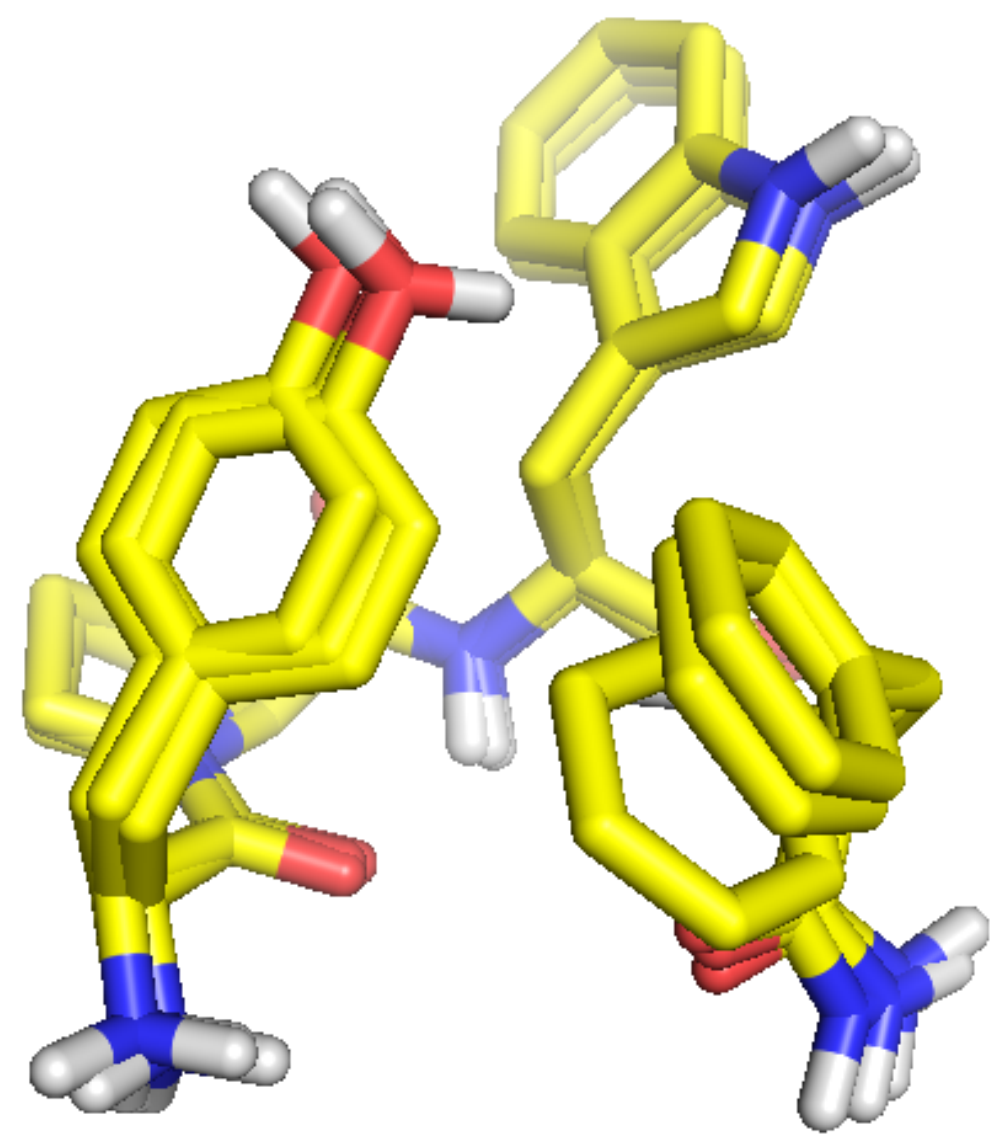

Figure S4. 25 lowest energy structures of peptide 1 in aqueous buffer. Coordinates of ensemble are included as a single PDB file with 25 states, average coordinates also included. Non-polar hydrogens omitted for clarity. 
Table S7. NMR Structure statistics for peptide 1 in aqueous buffer.

\begin{tabular}{l|l}
\hline NMR constraints & 21 \\
\hline Distance constraints & 19 \\
\hline Total NOE & 6 \\
Intra-residue & 13 \\
Inter-residue & 11 \\
Sequential $(i$ to $i+1)$ & 2 \\
Medium-range $(i$ to $i+2,3)$ & 0 \\
Intermolecular & 1 \\
Hydrogen bonds & \\
Total dihedral angle restraints & 0 \\
$\phi$ & 0 \\
$\psi$ & \\
Structure statistics & 0 \\
Violations (mean and s.d.) & $0.0363 \pm 0.0007$ \\
Distance constraints $(\mathrm{rmsd}, \AA)$ & 0 \\
Dihedral angle constraints $\left({ }^{\circ}\right)$ & $n / a$ \\
Max. dihedral angle violation $\left(^{\circ}\right)$ & 0 \\
Max. distance constraint violation $(\AA)$ & \\
Deviations from idealized geometry & \pm 0.0091 \\
Bond lengths $(\AA)$ & \pm 1.09 \\
Bond angles $\left({ }^{\circ}\right)$ & \pm 0.69 \\
Impropers $\left({ }^{\circ}\right)$ & \\
Average pairwise r.m.s. deviation $(\AA)(25$ Structures) & $0.6 \pm 0.4$ \\
Heavy & $0.1 \pm 0.1$ \\
Backbone & \\
\hline
\end{tabular}




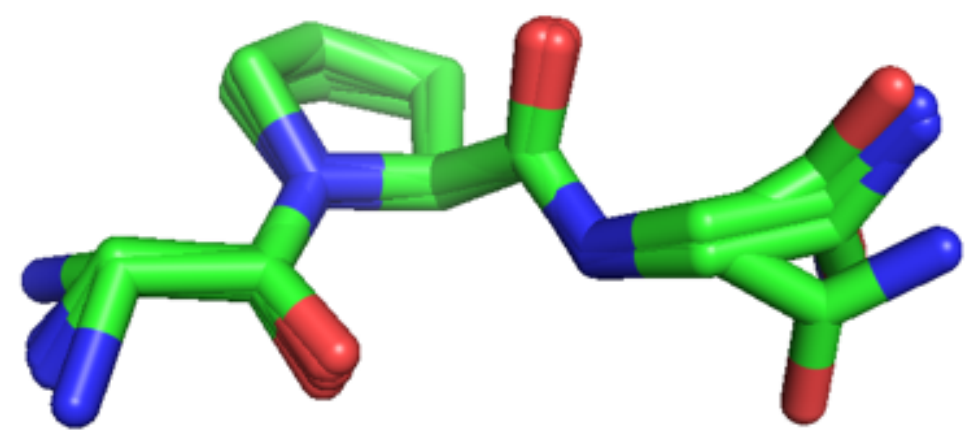

Figure S5. 25 lowest energy structures of the minor conformer of peptide 1 in $15 \mathrm{wt} \%$ DMPC/DHPC bicelles. Coordinates of ensemble are included as a single PDB file with 25 states, average coordinates also included. Sidechains and hydrogens omitted for clarity; Phe(4) was unrestrained in the calculation and is therefore omitted in the depiction above. 
Table S8. NMR Structure statistics for the minor conformer of peptide 1 in 15 wt \% DMPC/DHPC bicelles.

\begin{tabular}{l|l}
\hline NMR constraints & 20 \\
\hline Distance constraints & 18 \\
\hline Total NOE & 7 \\
Intra-residue & 11 \\
Inter-residue & 0 \\
Sequential $(i$ to $i+1)$ & 11 \\
Medium-range $(i$ to $i+2,3)$ & 0 \\
Intermolecular & 1 \\
Hydrogen bonds & \\
Total dihedral angle restraints & 0 \\
$\phi$ & 0 \\
$\psi$ & \\
Structure statistics & 0 \\
\hline Violations (mean and s.d.) & $0.0011 \pm 0.0004$ \\
Distance constraints $(\mathrm{rmsd}, \AA)$ & 0 \\
Dihedral angle constraints $\left(^{\circ}\right)$ & $n / a$ \\
Max. dihedral angle violation $\left(^{\circ}\right)$ & 0 \\
Max. distance constraint violation $(\AA)$ & \\
Deviations from idealized geometry & \pm 0.0055 \\
Bond lengths $(\AA)$ & \pm 0.44 \\
Bond angles $\left({ }^{\circ}\right)$ & \pm 0.271 \\
Impropers $\left({ }^{\circ}\right)$ & \\
Average pairwise r.m.s. deviation $(\AA)(25$ Structures) & $2.5 \pm 1.0$ \\
\hline Heavy & $0.6 \pm 0.5$ \\
Backbone & \\
\hline
\end{tabular}




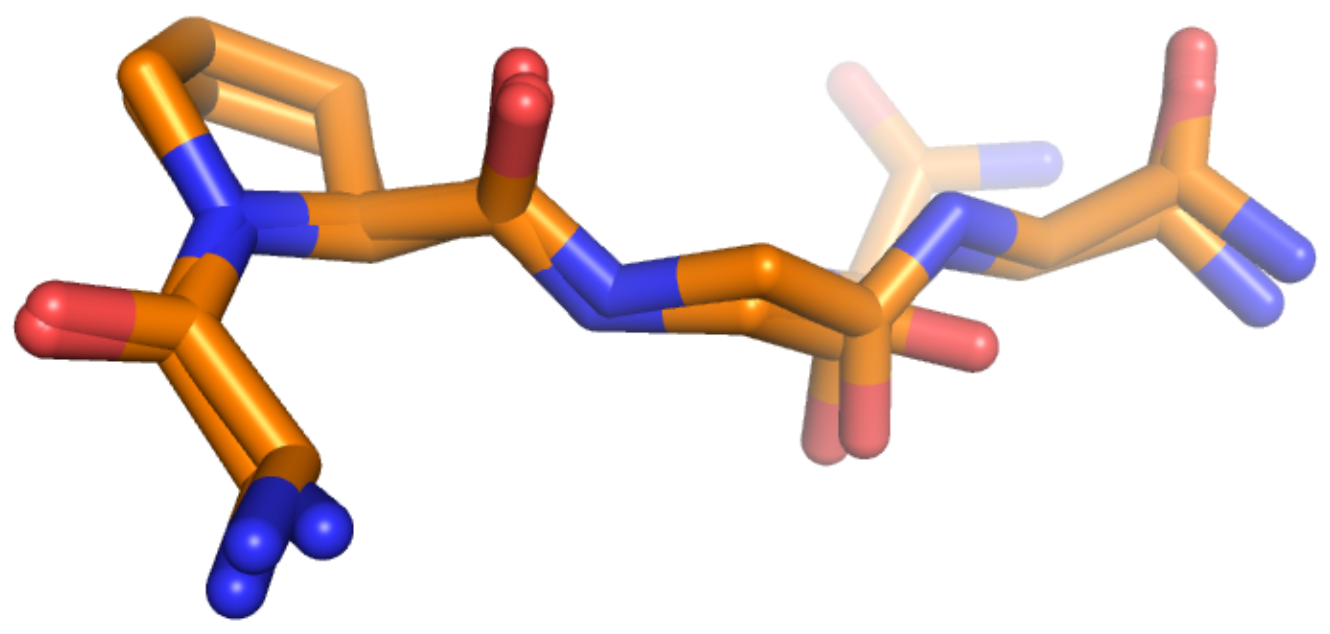

Figure S6. 25 lowest energy structures of the major conformer of peptide 1 in 15 wt \% DMPC/DHPC bicelles, featuring a cis tyrosine(1)-proline(2) amide bond configuration. Coordinates of ensemble are included as a single PDB file with 25 states. Hydrogens and sidechains are omitted for clarity. 
Table S9. NMR Structure statistics for the major conformer of peptide 1 in 15 wt \% DMPC/DHPC bicelles, using a cis tyrosine(1)-proline(2) amide bond configuration.

\begin{tabular}{l|l}
\hline NMR constraints & 19 \\
\hline Distance constraints & 21 \\
\hline Total NOE & 10 \\
Intra-residue & 11 \\
Inter-residue & 5 \\
Sequential $(i$ to $i+1)$ & 6 \\
Medium-range $(i$ to $i+2,3)$ & 0 \\
Intermolecular & 0 \\
Hydrogen bonds & \\
Total dihedral angle restraints & 0 \\
$\phi$ & \\
$\psi$ & \\
Structure statistics & 0 \\
\hline Violations (mean and s.d.) & \pm 0.029 \\
Distance constraints $($ rmsd, $\AA$ ) & 0 \\
Dihedral angle constraints $\left({ }^{\circ}\right)$ & $n / a$ \\
Max. dihedral angle violation $\left({ }^{\circ}\right)$ & 0 \\
Max. distance constraint violation $(\AA)$ & \\
Deviations from idealized geometry & \pm 0.0072 \\
Bond lengths $(\AA)$ & \pm 0.65 \\
Bond angles $\left({ }^{\circ}\right)$ & \pm 0.28 \\
Impropers $\left({ }^{\circ}\right)$ & \\
Average pairwise $r . m . s$. deviation $(\AA)(25$ Structures) & $1.2 \pm 1.0$ \\
\hline Heavy & $0.2 \pm 0.3$ \\
Backbone & \\
\hline
\end{tabular}


IVe. NMR Spectra for Peptide 1

Note: Unless otherwise indicated, the spectra that follow were collected at $600 \mathrm{MHz}$ and 298K.

$1 D^{1} \mathrm{H}$ NMR Spectrum for Peptide 1

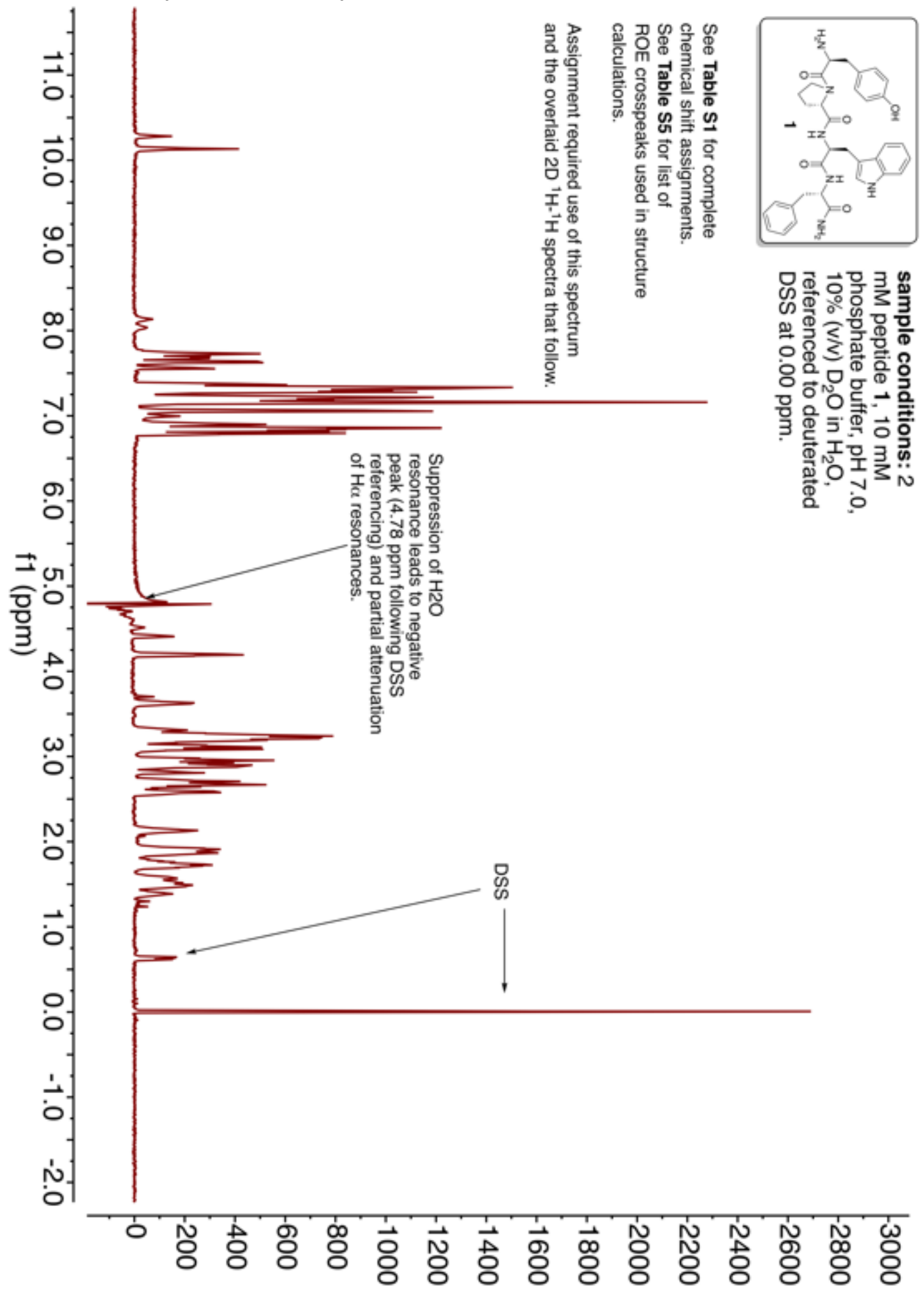




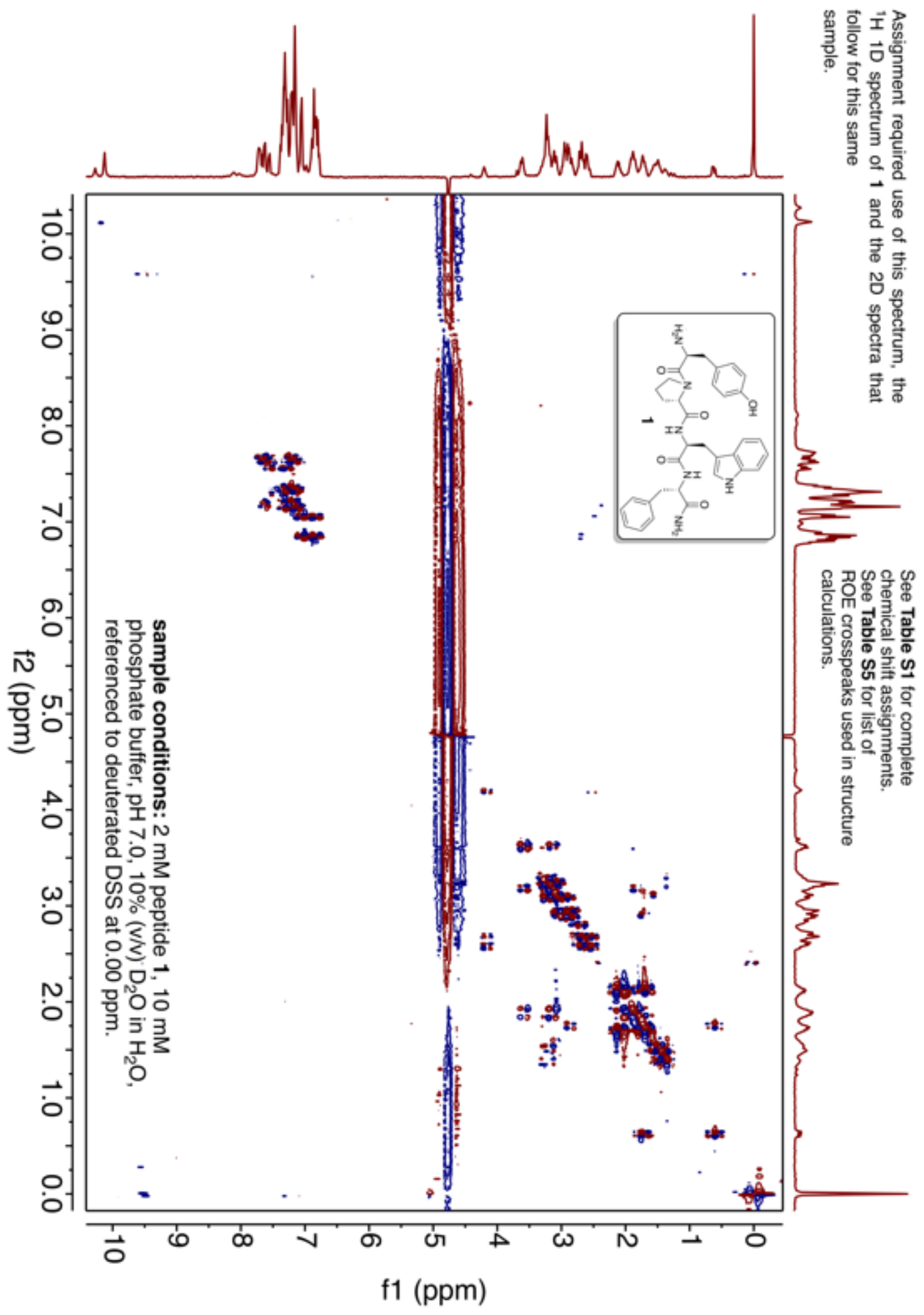




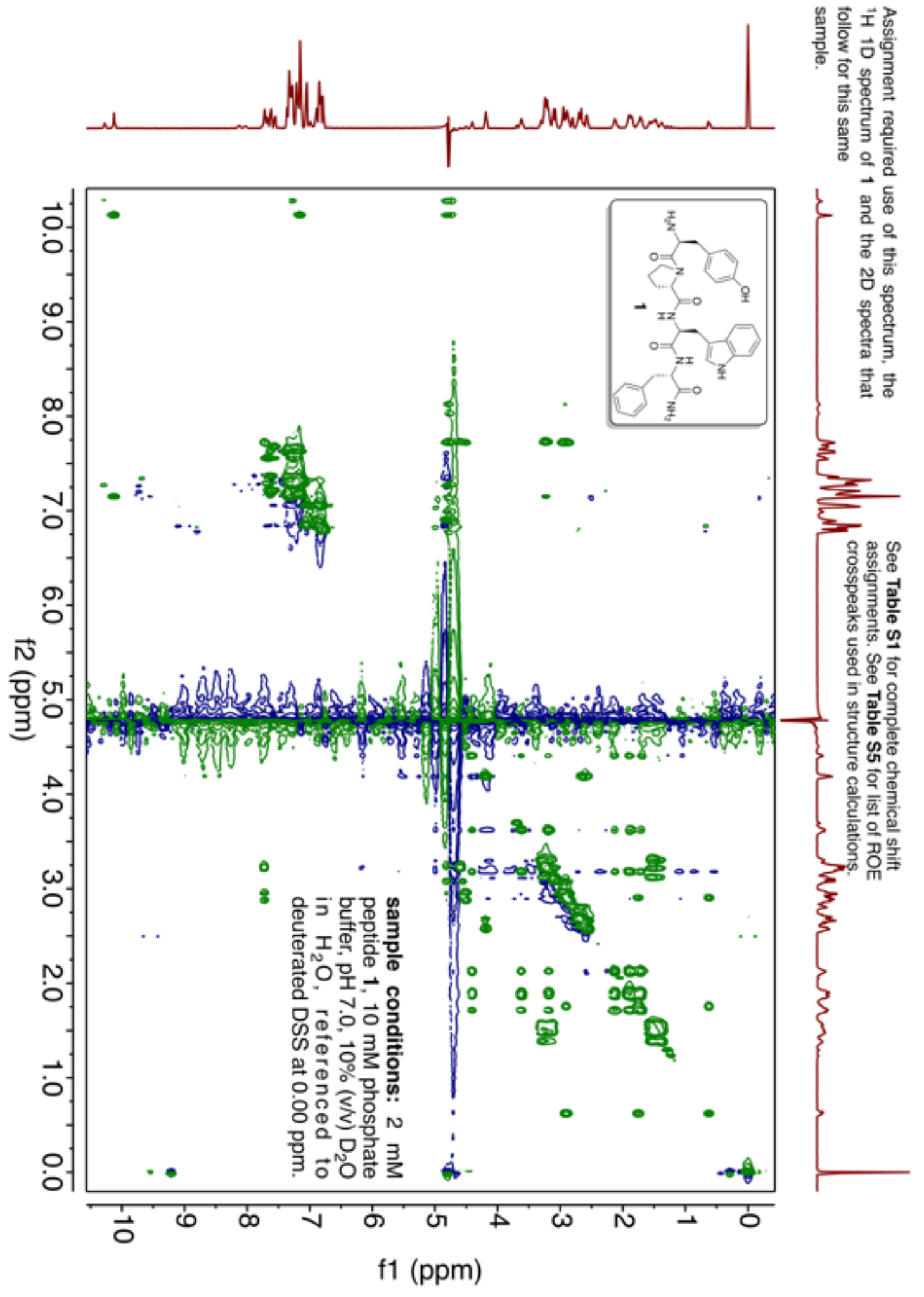




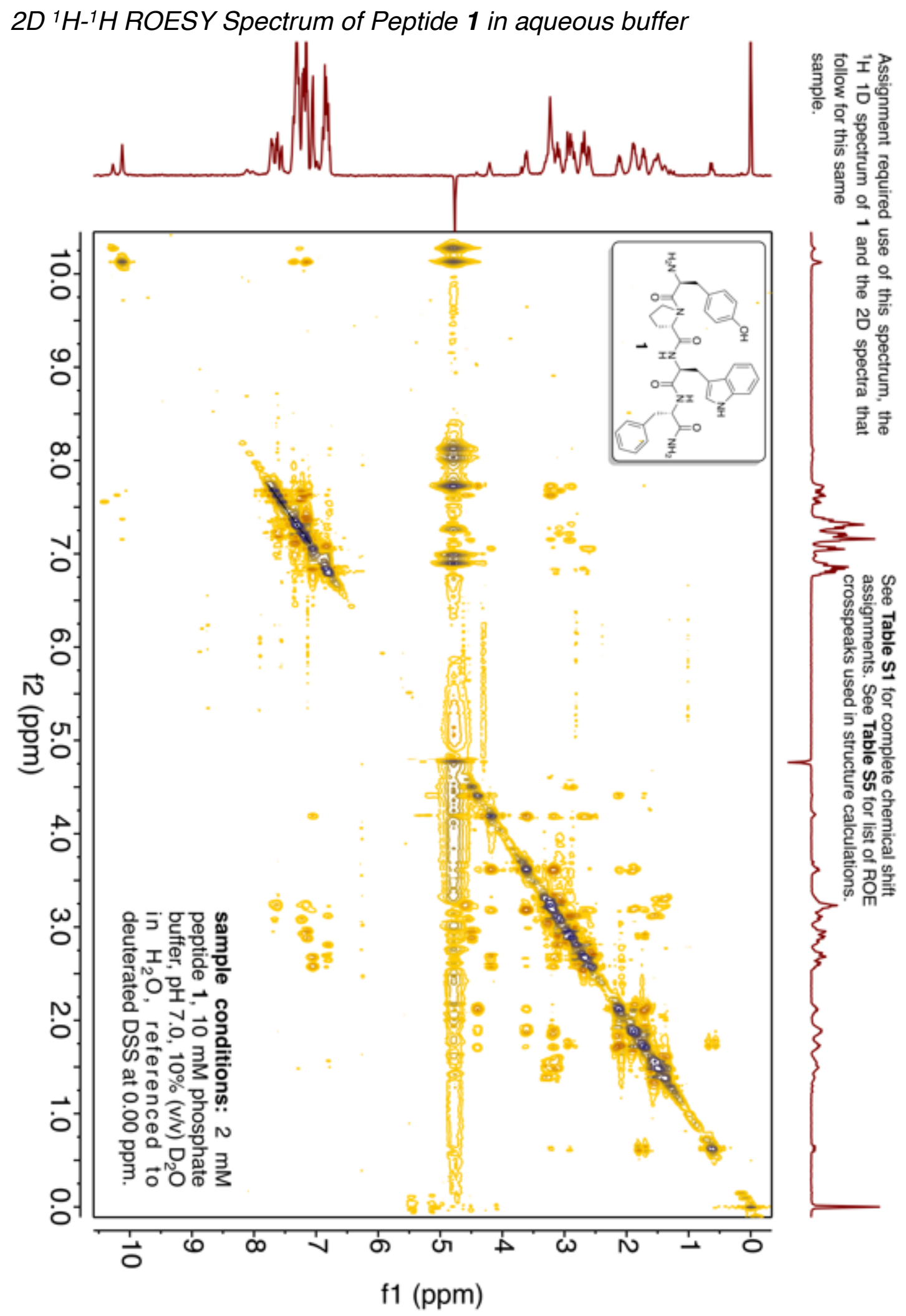


Zoomed in example from COSY/TOCSY/ROESY overlay used to assign the resonances of peptide 1 in aqueous buffer (Mestrenova software)

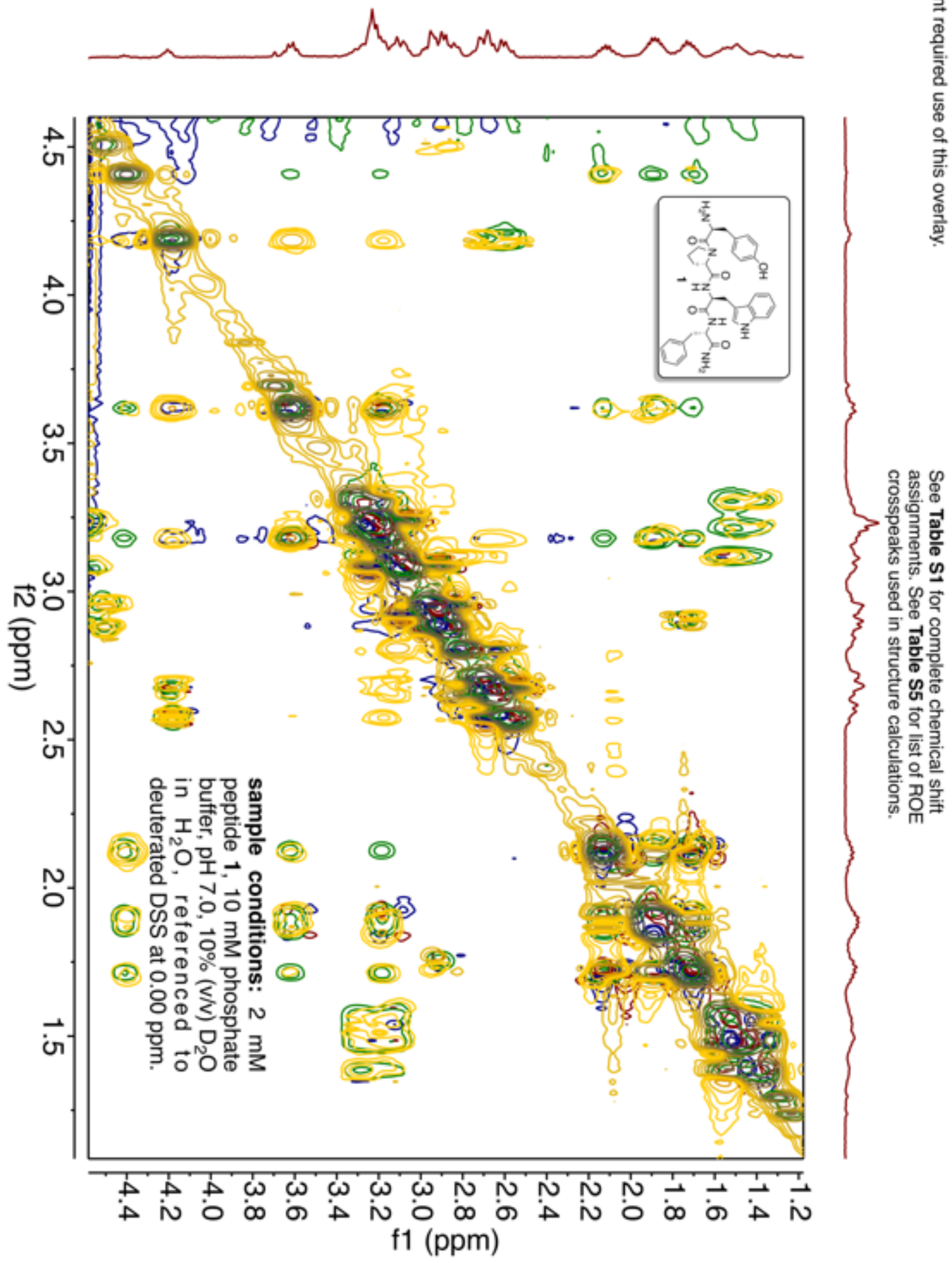




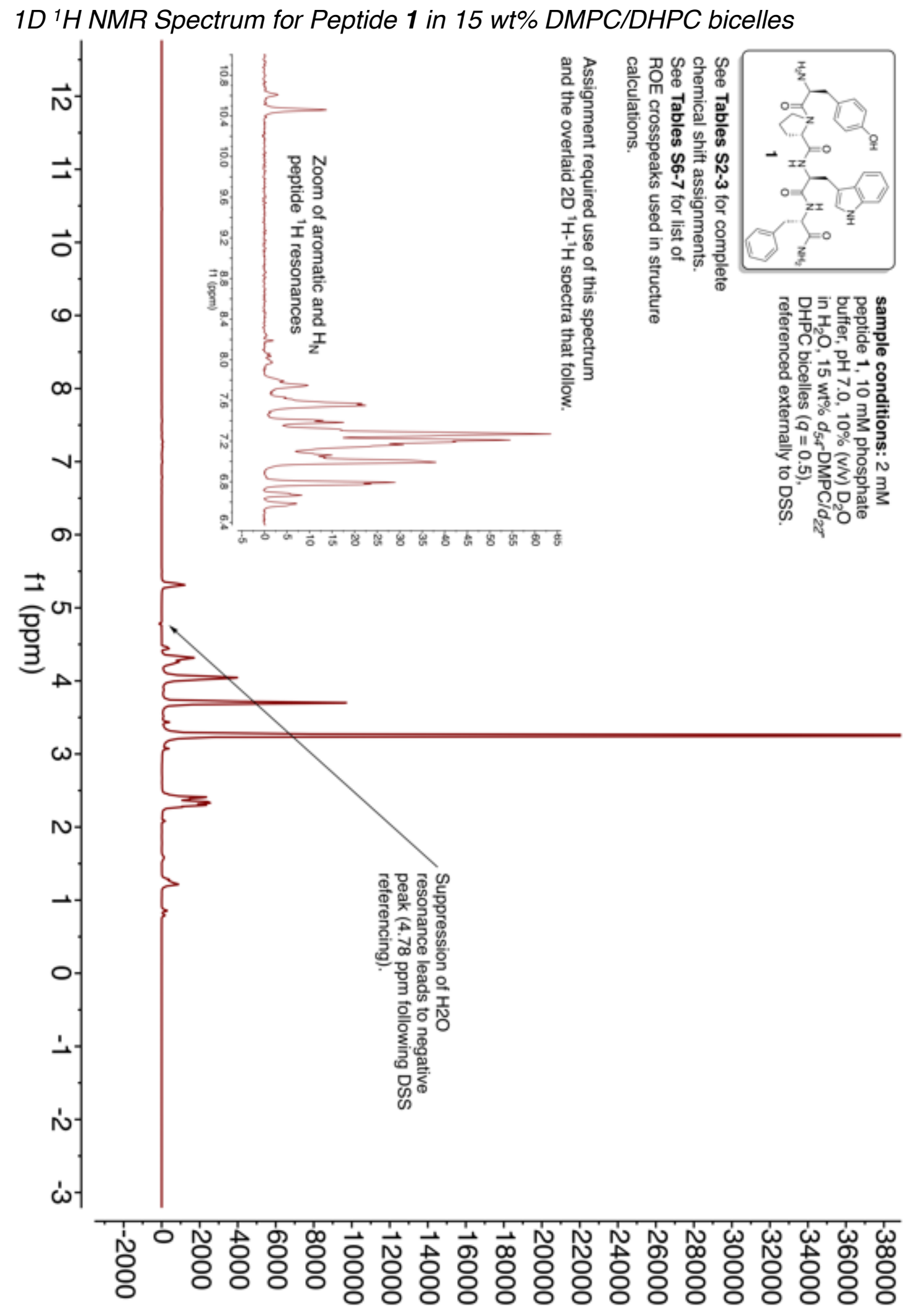


$2 D^{1} \mathrm{H}^{-1} \mathrm{H}$ COSY Spectrum of Peptide 1 in $15 \mathrm{wt} \%$ DMPC/DHPC bicelles

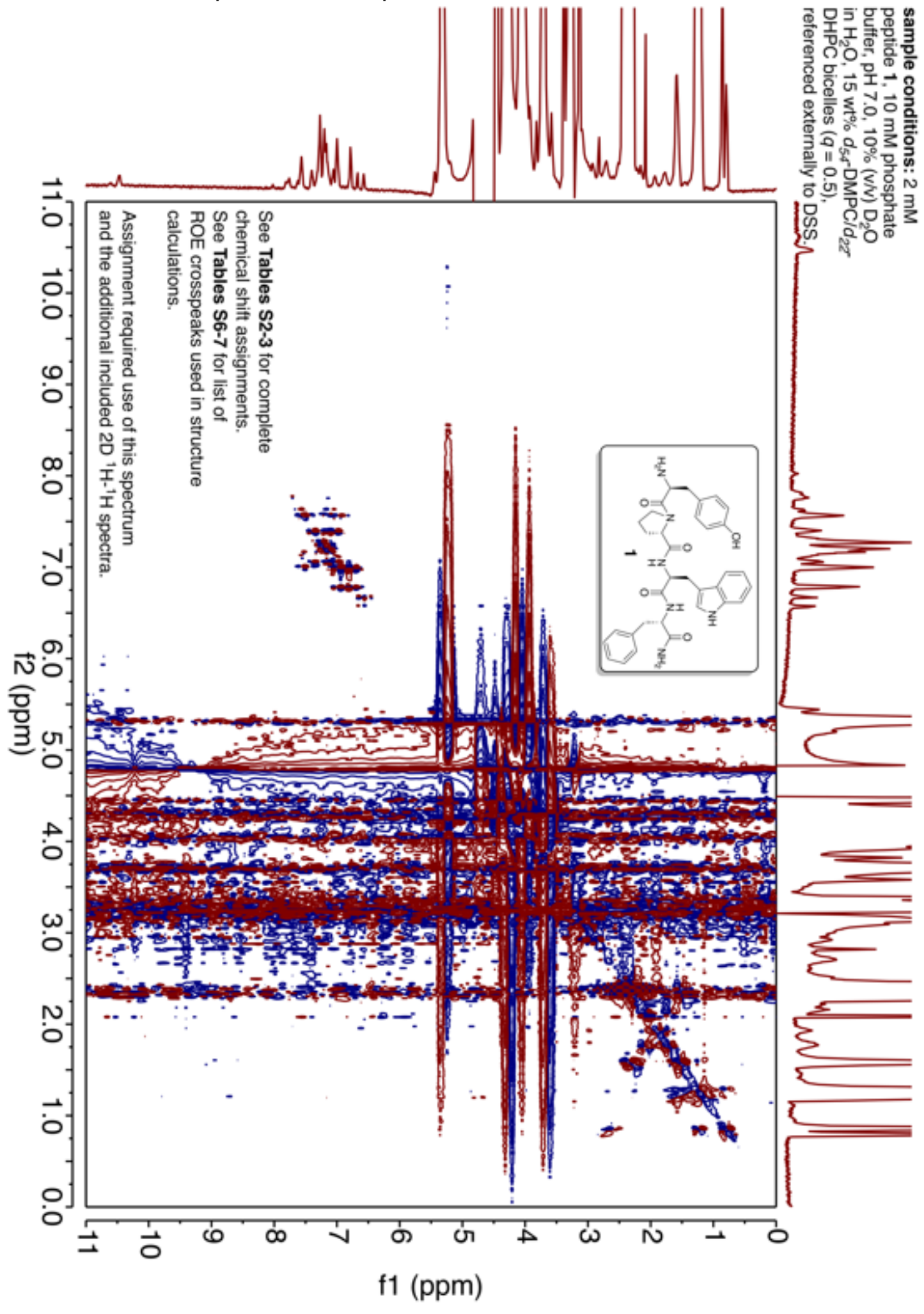


$2 D^{1} \mathrm{H}^{1} \mathrm{H}$ TOCSY Spectrum of Peptide 1 in $15 \mathrm{wt} \%$ DMPC/DHPC bicelles

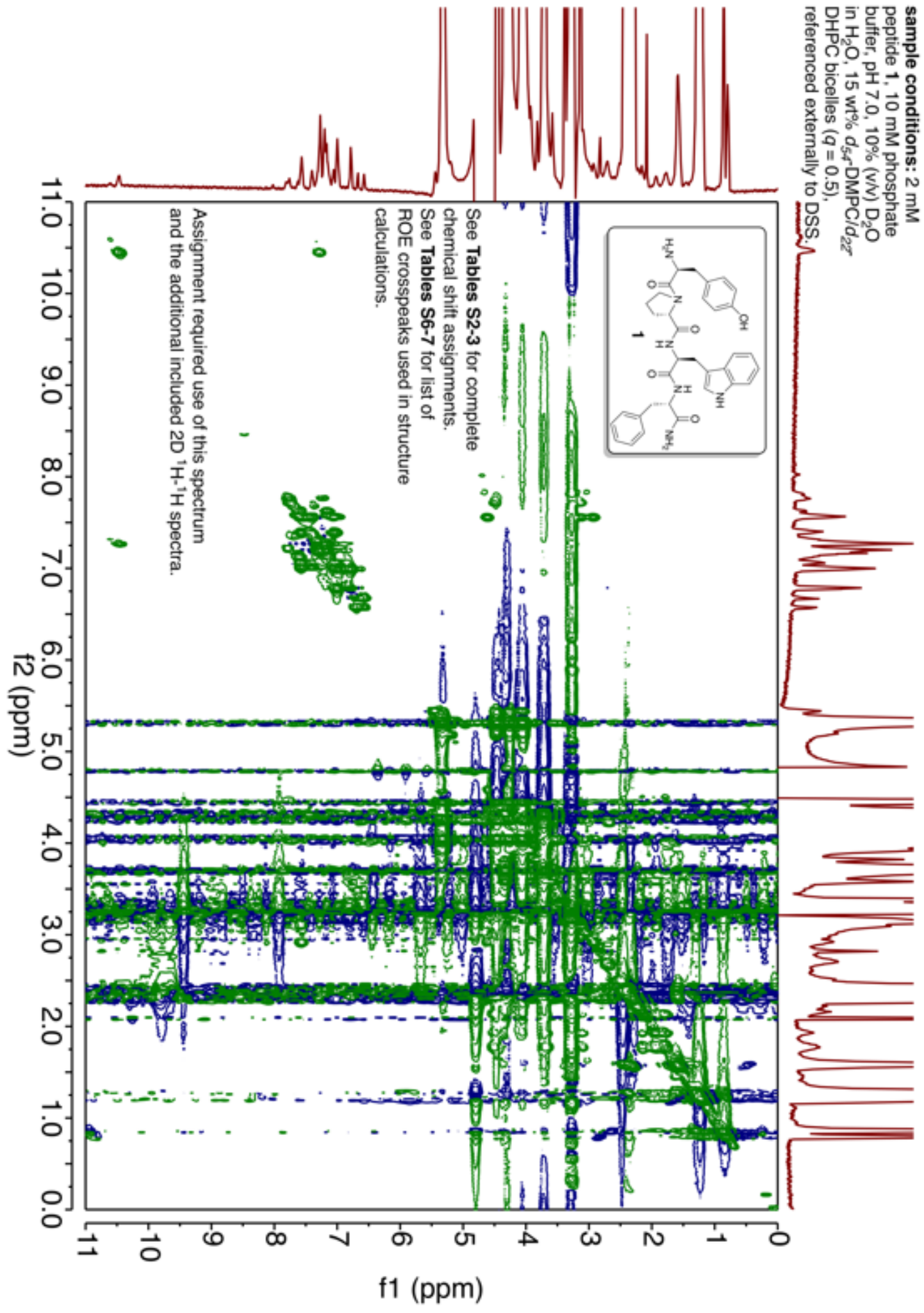


$2 D^{1} \mathrm{H}^{1} \mathrm{H}$ NOESY Spectrum of Peptide 1 in $15 \mathrm{wt} \%$ DMPC/DHPC bicelles

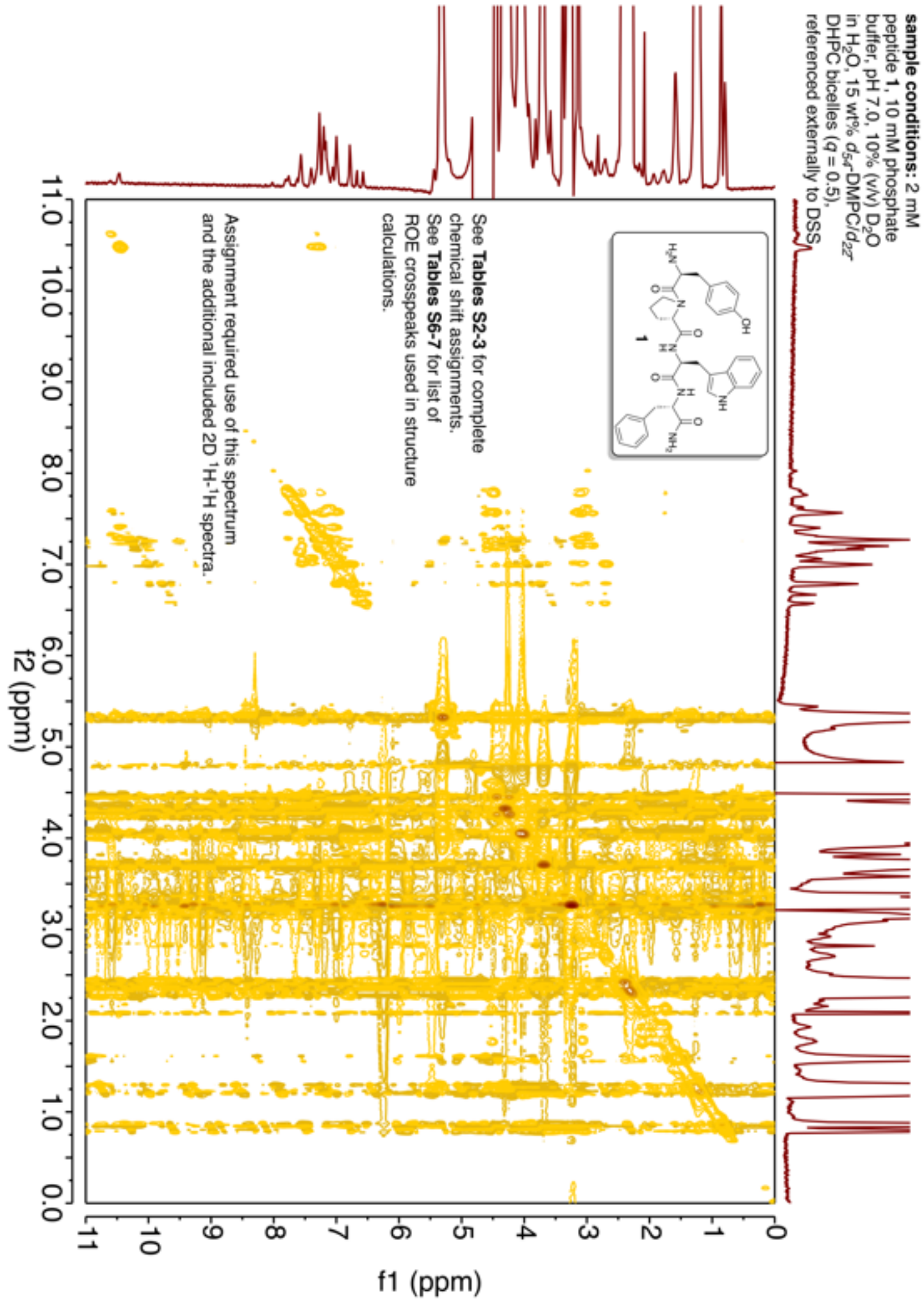


Zooms of overlaid 2D ${ }^{1} \mathrm{H}^{-1} \mathrm{H}$ NMR Spectra of Peptide 1 in $15 \mathrm{wt} \%$ DMPC/DHPC bicelles used to assign the sequence and identify NOESY crosspeaks for distance restraints sample conditions: $2 \mathrm{mM}$ peptide $1,10 \mathrm{mM}$ phosphate bufter, $\mathrm{pH} 7.0,10 \%$ (viN) $\mathrm{D}_{2} \mathrm{O}$

in $\mathrm{H}_{2} \mathrm{O}, 15$ wt\% $d_{5 r} \mathrm{DMPC} / d_{22}$

DHPC bicelles $(q=0.5)$,

referenced externally to DSS.
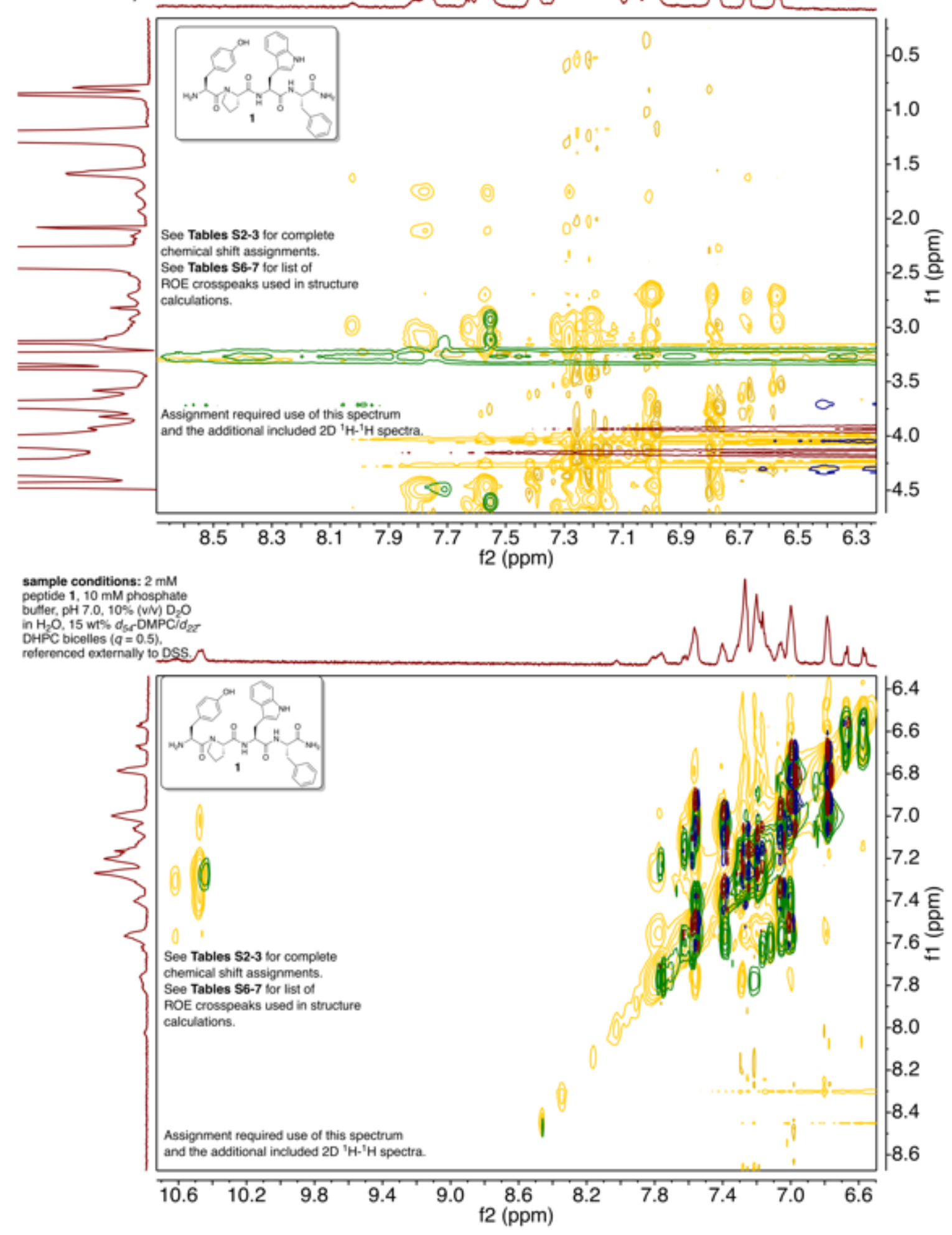
IVf. DOSY NMR Spectra for Peptide 1

Peptide sample conditions: $2 \mathrm{mM}$ peptide 1, $10 \mathrm{mM}$ phosphate buffer, $\mathrm{pH} 7.0,10 \%$ (v/v) $\mathrm{D}_{2} \mathrm{O}$ in $\mathrm{H}_{2} \mathrm{O}$, referenced externally to DSS.

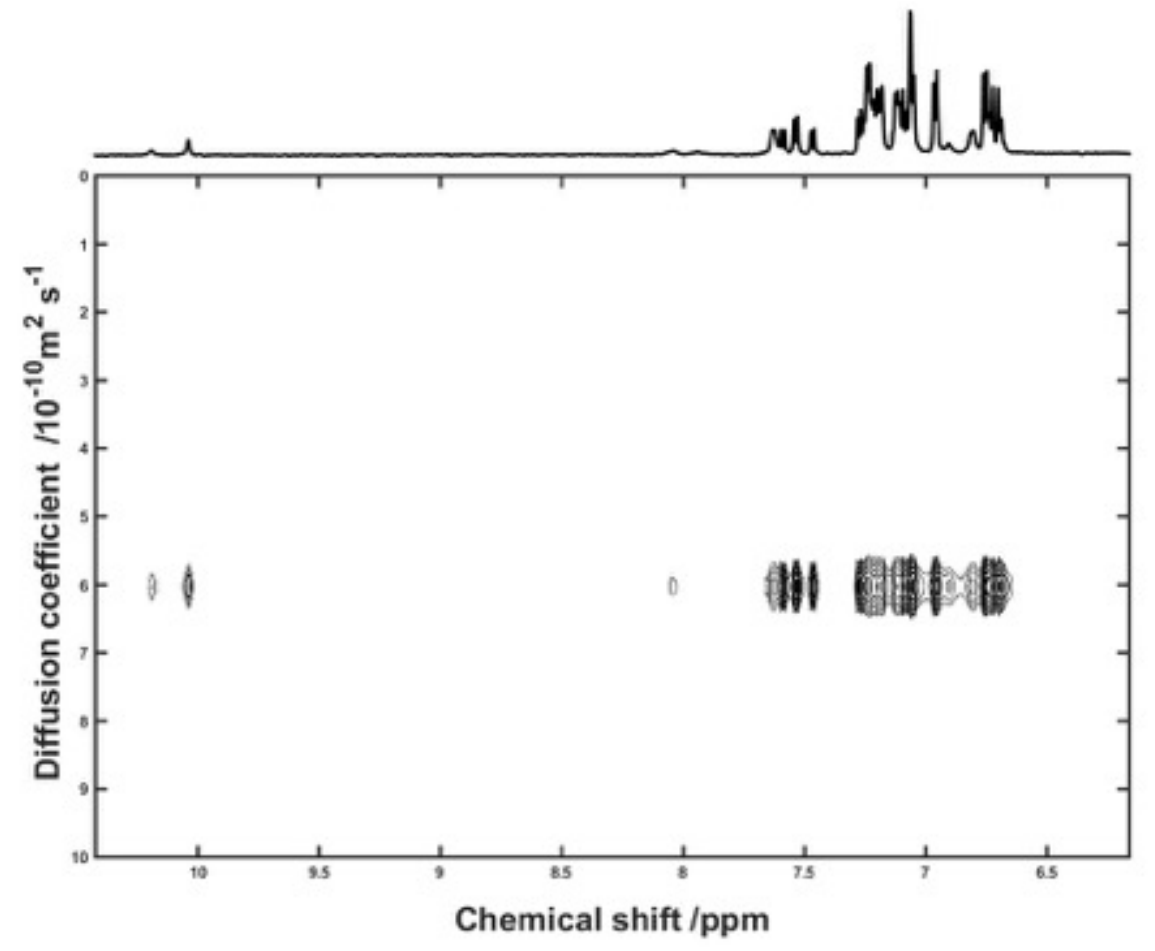

Lipid sample conditions: $15 \mathrm{wt} \%$ d54-DMPC/d22-DHPC bicelles $(q=0.5), 10 \mathrm{mM}$ phosphate buffer, $\mathrm{pH} 7.0,10 \%(\mathrm{v} / \mathrm{v}) \mathrm{D}_{2} \mathrm{O}$ in $\mathrm{H}_{2} \mathrm{O}$, referenced externally to DSS.

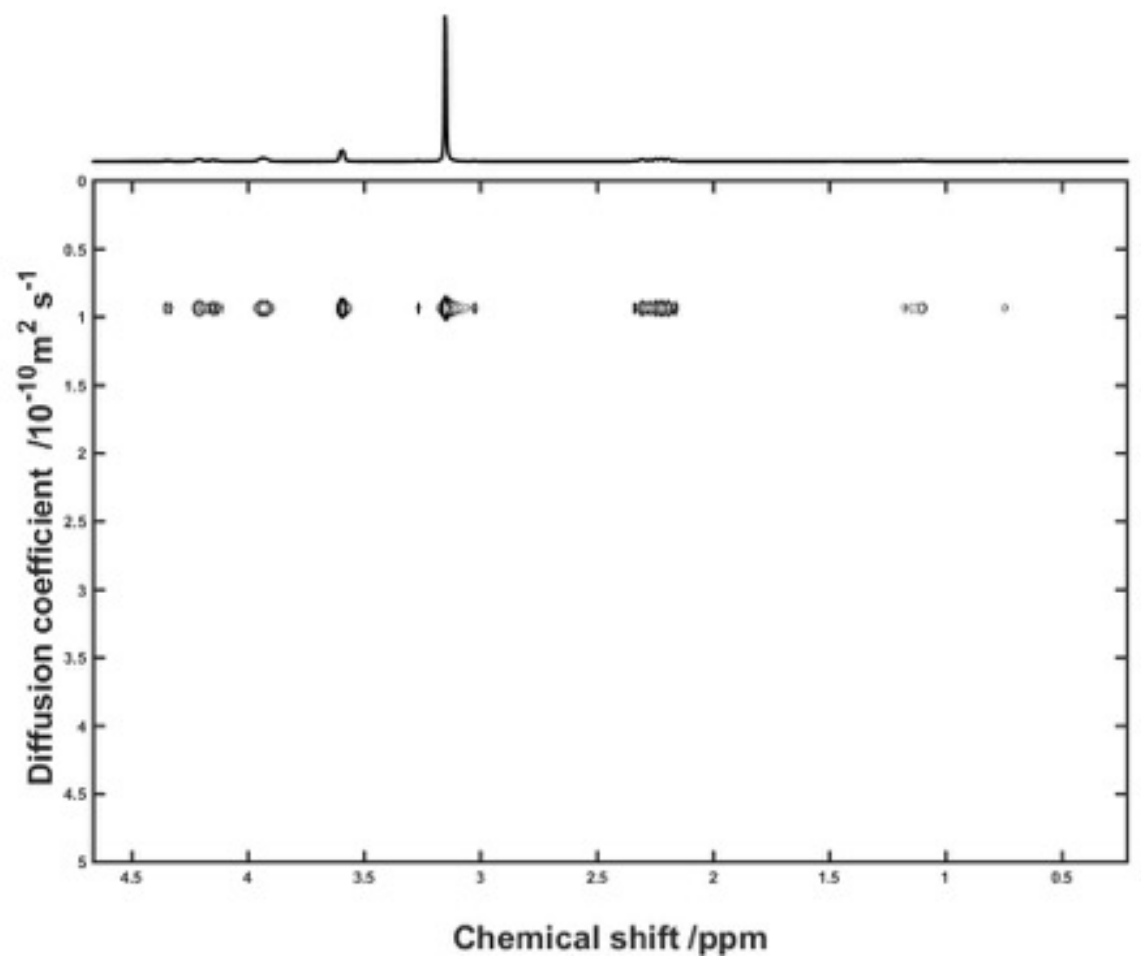


Mixed sample conditions: $2 \mathrm{mM}$ peptide 1, $15 \mathrm{wt} \%$ d54-DMPC/d22-DHPC bicelles ( $\mathrm{q}=$ 0.5), $10 \mathrm{mM}$ phosphate buffer, $\mathrm{pH} 7.0,10 \%(\mathrm{v} / \mathrm{v}) \mathrm{D}_{2} \mathrm{O}$ in $\mathrm{H}_{2} \mathrm{O}$, referenced externally to DSS.

Peptide resonances in mixed sample:

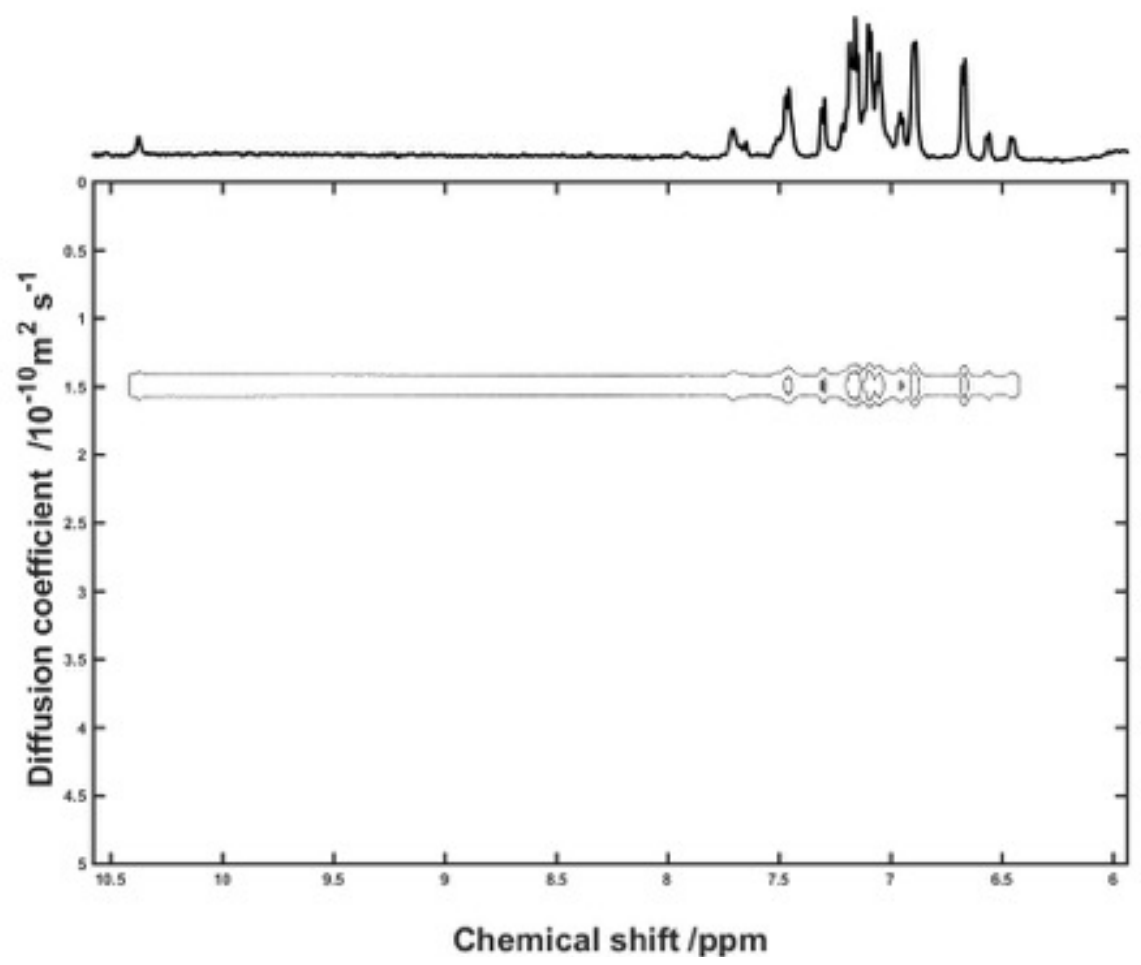

Lipid resonances in mixed sample:

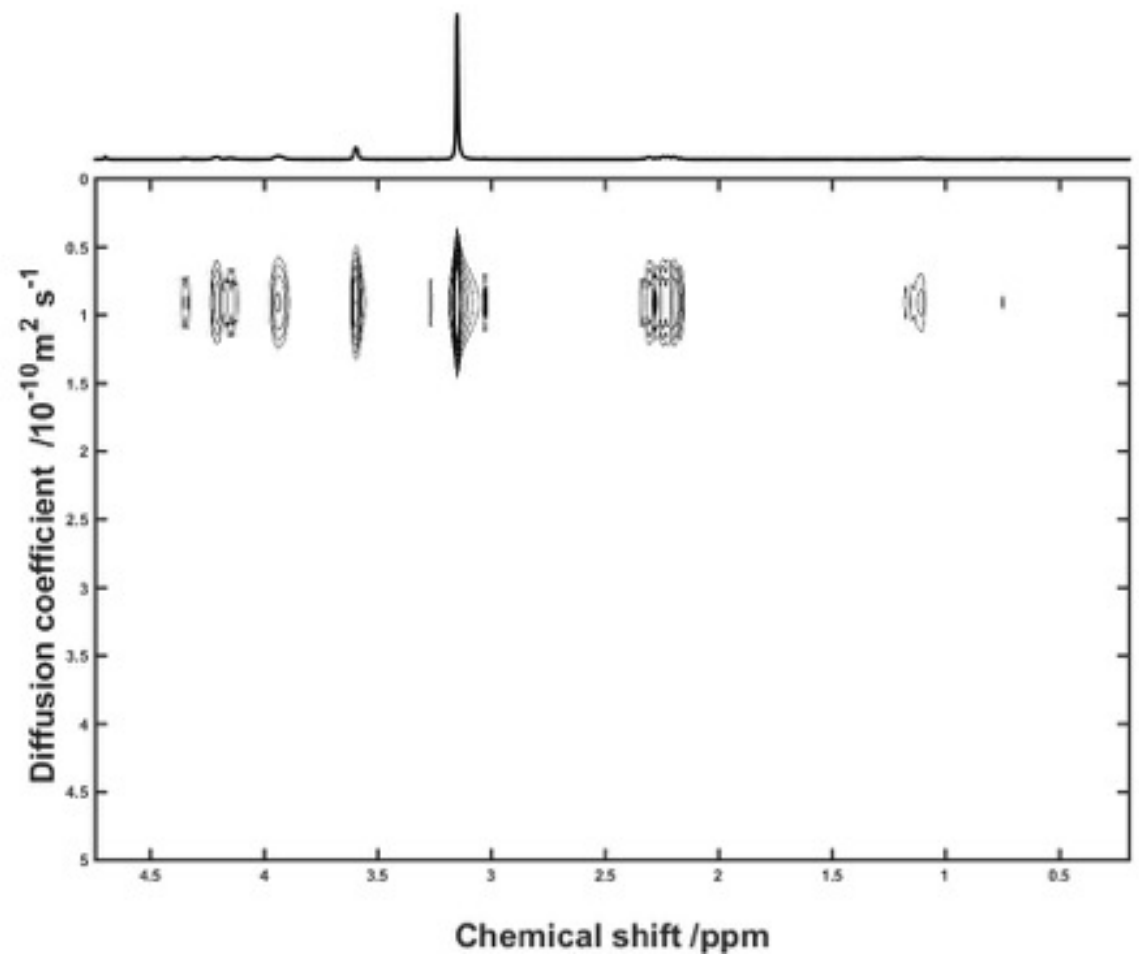




\section{Fluorescence Spectra for Peptide 1}

Sample Conditions: $50 \mu \mathrm{M}$ peptide 1, $10 \mathrm{mM}$ phosphate buffer, $\mathrm{pH} 7.0,15$ wt $\%$ DMPC/DHPC bicelles, $q=0.5$

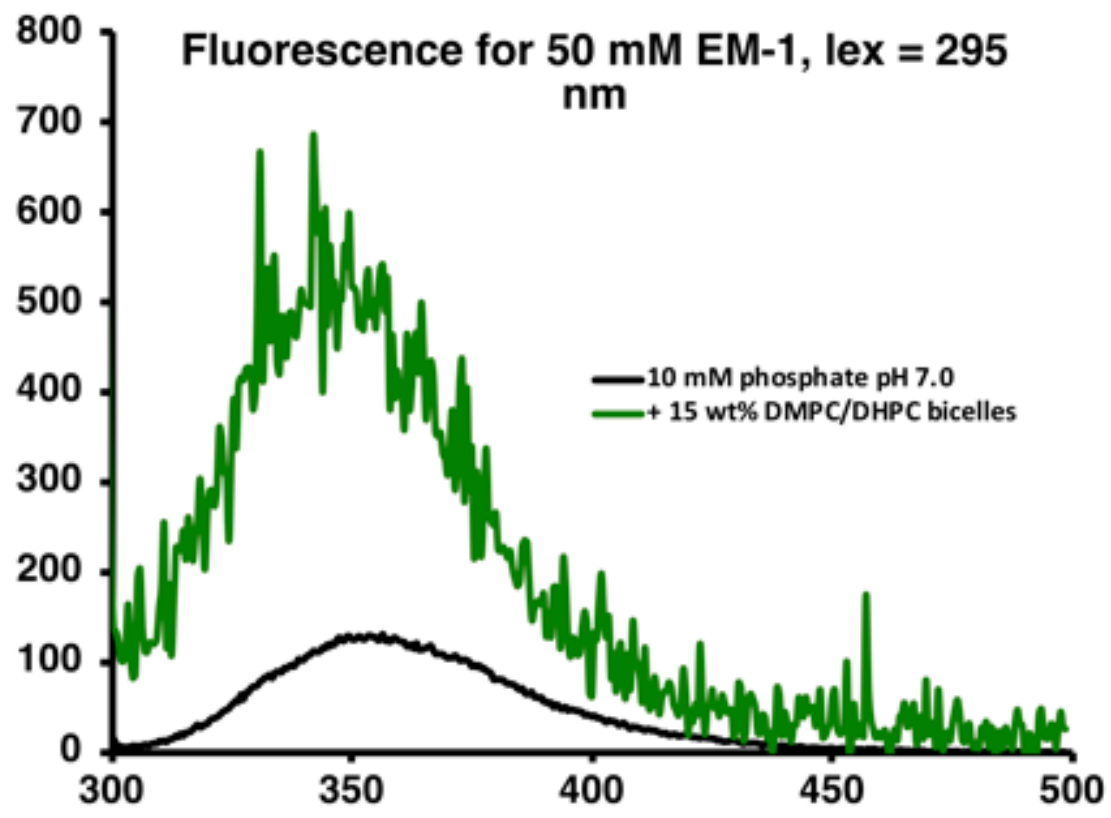

Sample Conditions: $250 \mu \mathrm{M}$ peptide 1, $10 \mathrm{mM}$ phosphate buffer, $\mathrm{pH} 7.0,15$ wt\% DMPC/DHPC bicelles, $q=0.5$

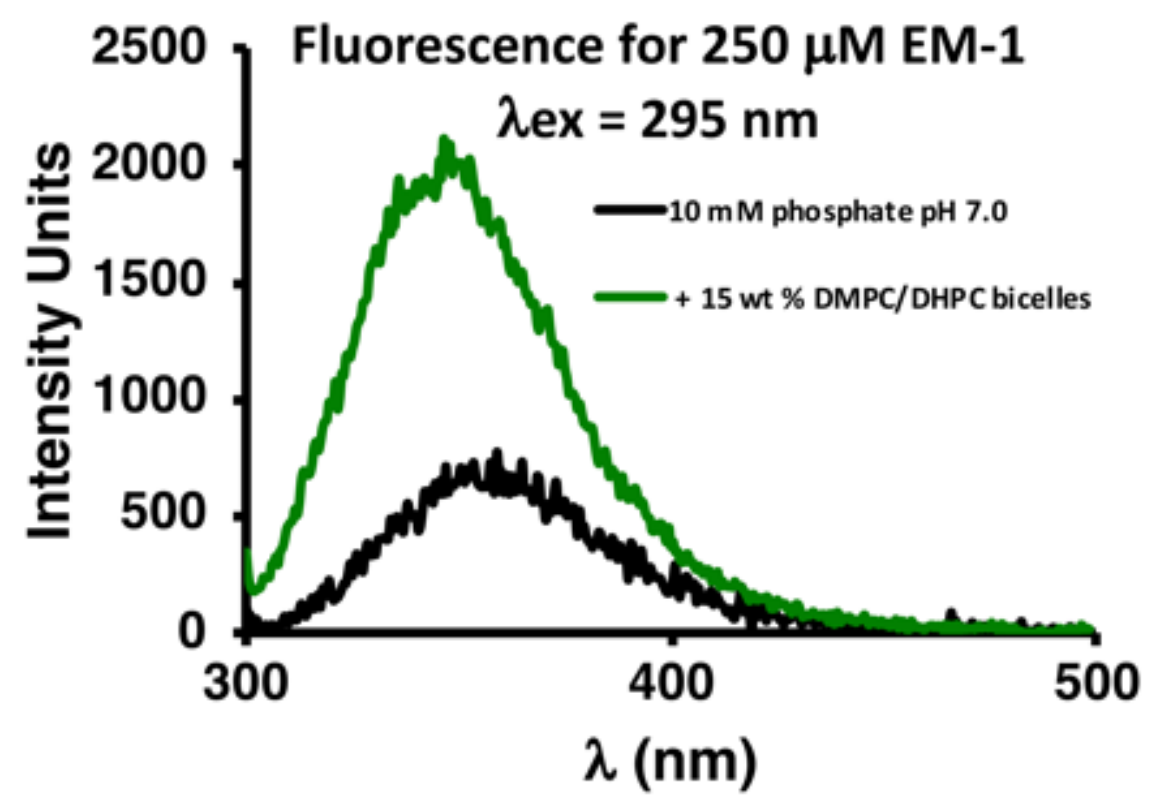




\section{References}

1. The PyMOL Molecular Graphics System, Version 1.8.2.2 Schrödinger, LLC.

2. Brunger, A. T.; Adams, P. D.; Clore, G. M.; DeLano, W. L.; Gros, P.; Grosse-Kunstleve, R. W.; Jiang, J. S.; Kuszewski, J.; Nilges, M.; Pannu, N. S.; Read, R. J.; Rice, L. M.; Simonson, T.; Warren, G. L., Crystallography \& NMR system: A new software suite for macromolecular structure determination. Acta Crystallographica Section D-Biological Crystallography 1998, 54, 905-921. 3. Brunger, A. T., Version 1.2 of the Crystallography and NMR system. Nat. Protoc. 2007, 2 (11), 2728-2733.

4. Humphrey, W.; Dalke, A.; Schulten, K., VMD: Visual molecular dynamics. Journal of Molecular Graphics \& Modelling 1996, 14 (1), 33-38.

5. Phillips, J. C.; Braun, R.; Wang, W.; Gumbart, J.; Tajkhorshid, E.; Villa, E.; Chipot, C.; Skeel, R. D.; Kale, L.; Schulten, K., Scalable molecular dynamics with NAMD. Journal of Computational Chemistry 2005, 26 (16), 1781-1802.

6. Cavanagh, J.; Fairbrother, W. J.; Palmer, A. G.; Rance, M.; Skelton, N. J., CHAPTER 10 SEQUENTIAL ASSIGNMENT, STRUCTURE DETERMINATION, AND OTHER APPLICATIONS. In Protein NMR Spectroscopy (Second Edition), Cavanagh, J.; Fairbrother, W. J.; Palmer, A. G.; Rance, M.; Skelton, N. J., Eds. Academic Press: Burlington, 2007; pp 781-817.

7. Cavanagh, J.; Fairbrother, W. J.; Palmer, A. G.; Rance, M.; Skelton, N. J., CHAPTER 9 - LARGER PROTEINS AND MOLECULAR INTERACTIONS. In Protein NMR Spectroscopy (Second Edition), Cavanagh, J.; Fairbrother, W. J.; Palmer, A. G.; Rance, M.; Skelton, N. J., Eds. Academic Press: Burlington, 2007; pp 725-780.

8. Wüthrich, K., NMR of Proteins and Nucleic Acid. Wiley: New York, 1986.

9. Ho, B. K.; Coutsias, E. A.; Seok, C.; Dill, K. A., The flexibility in the proline ring couples to the protein backbone. Protein Science 2005, 14 (4), 1011-1018. 